\title{
Symmetric and asymmetric motivations for compliance and violation: A crisp set qualitative comparative analysis (csQCA) of Chinese farmers
}

Huiqi Yan, Jeroen van der Heijden, Benjamin van Rooij

\begin{abstract}
This article applies crisp set qualitative comparative analysis (csQCA) to gain insight in the compliance motivations and compliance behaviours of 101 Chinese farmers. It seeks to understand how eight motivations (capacity to comply, legal knowledge, deterrent effect of sanctions, costbenefit analysis, descriptive social norms, morals, general duty to obey, and procedural justice) combine in compliant and non-compliant behaviour, and whether there is only one combination of motivations or several that lead to compliance and non-compliance. It illustrates how cSQCA assists in making visible and analyzing situations of interacting compliance motivations (conjunctural causality) and situations where different combinations of motivations result in similar compliance behaviour (equifinality). It identifies symmetrical and non-symmetrical relationships between specific compliance motivations and compliance behaviours-indicating that motivations for non-compliance are not necessarily the opposite of those for compliance. This non-symmetry may logically be explained because deterrence plays a different role in compliance decisions than in non-compliance decisions. The article concludes by highlighting the relevance of such insights for theorizing on compliance and for law enforcement, and the limitations of the method applied.
\end{abstract}

\section{Keywords}

Compliance motivations, pesticide regulation, enforcement, China, crisp set qualitative comparative analysis (csQCA)

\section{Introduction}

A key question of regulation and governance scholarship is why individuals and organisations obey or violate the law (Tyler 1990). To answer it, scholars have studied conditions considered to affect compliance, such as the deterring effect of sanctions or a general duty to obey the law by individuals and organisations (further: regulatees). They point out that it is very difficult, if not impossible, to trace 'the' single condition that best explains compliance. More likely, conditions interact in causing compliant behaviour (i.e., conjunctural causation) and different (combinations of) conditions can simultaneously contribute to compliant behaviour (i.e., equifinality) (Ayres \& Braithwaite 1992; Gunningham et al. 2003; Lehmann Nielsen \& Parker 2012).

Understanding it is unlikely that a single motivation best explains compliance or noncompliance, scholars often develop typologies that bring together different (sets of) compliance motivations in a number of types. Their typologies can be broadly clustered in two groups: 'ideal types' and '(narrow) patterns'. Ideal types seek to present a holistic understanding of compliance behaviour. Their value lies in their 'elegance' (cf., Van der Berg 2003): Regulatees are clustered in types that are loosely built on compliance motivations identified in the literature, and the types are so general that they can be used as descriptors in a wide range of contexts. These typologies come, 
however, with some critiques (May 2005; Parker \& Nielsen 2009): They easily become subject to a 'too many variables, too few observations' problem, which reduces their (empirical) reach and explanatory value (cf., Lijphart 1971).

In the second group, (narrow) patterns, typologies are often built on systematic studies that focus on a confined number of compliance motivations, and sophisticated statistical data analysis techniques are used to arrive at typologies that best fit the compliance data collected. Whilst less elegant than the typologies in the first group (cf., Van der Berg 2003), their value lies in their analytical rigour. These typologies, however, face critiques as well (May 2005; Parker \& Nielsen 2009): They often rely on (self-reported) survey data, and the validity of such data is questioned because it relies on the willingness of regulatees to provide trustworthy insights regarding their compliance behaviour-a highly sensitive issue (Cialdini 2003; Elffers et al. 1987).

Whilst appreciating and being inspired by both sets of typologies, we wonder if another approach to studying compliance helps to address the weaknesses discussed. This was a relevant question when we began a study on Chinese farmers' compliance with pesticide regulation in 2011. We selected qualitative comparative analysis (QCA) for our data analysis-informed by earlier experience with the method (Anonymous 2009; 2015a) - because it helps us to better understand situations in which conjunctural caustation and equifinality are at play, and in which an in-depth understanding of a medium-size set of cases is sought through rich qualitative data (Ragin 2008; Rihoux \& Ragin 2009; Schneider \& Wagemann 2012). We have collected data though in-depth interviews, aiming to overcome the validity problem discussed.

In this article, we present the key findings from our study. We find that motivations that explain compliance are not always the inverse of motivations that explain non-compliance. This goes against an implicit assumption in the literature and many dominant typologies, i.e., that compliance and non-compliance are symmetrically influenced by compliance motivations. We find a specific cluster of motivations that indeed affects compliance and non-compliance symmetrically-the combination of law as a source of moral authority, descriptive social norms to comply, and a positive cost benefit analysis. However, for an important compliance motivation-the deterrent effect of sanctions-we find an asymmetric relation with compliance.

The article unfolds as follows. The following section discusses the motivations that recur in the literature as related to compliance and non-compliance, and it further explores the two groups of typologies. We then introduce the research design of our study. Next, we present the main findings on compliant and non-compliant farmers. We conclude with a discussion of the implications for compliance theorising and insights on the method applied-including how it helps to address some of the shortfalls of dominant compliance typologies.

\section{Understanding compliance: motivations and typologies}

Compliance studies have moved well beyond the traditional deterrence model that was in vogue until the 1980s. It held that compliance results from a fear of the consequences of being found in violation of the law (Hawkins 1984; Reiss 1984). More recently, scholars have pointed towards a broader suite of interacting motivations that may explain compliant and non-compliant behaviour. A number of these motivations are dominant in the literature.

A first cluster of compliance motivations considers whether regulatees are able to comply. After all, they may lack the capacity to comply because of their physical characteristics or economic circumstances (Greer \& Downey 1981; Winter \& May 2001). They may further lack the legal knowledge required to comply (Winter \& May 2001). A large body of literature on legal literacy and 
legal awareness has developed which seeks to understand how governmental and other actors can improve regulatees' legal knowledge (Fletcher et al. 2005; Williams 2005).

A second cluster of motivations considers the deterrent effect of sanctions. It holds that the threat of sanctions motivates regulatees to comply with legal and regulatory requirements (Becker \& Stigler 1974; Hawkins 1984; Thornton et al. 2005). Expanding this traditional view (Hawkins 1984), this threat is now often unpacked as a (perceived) probability of being found in violation, a (perceived) probability of being sanctioned when found in violation, and a (perceived) sanction impact (Kirk \& Hawkins 1986; Nagin 2013). Following on from such insights, scholars consider procedural justice another motivation for compliance (Tyler 1990). The day-to-day aspects of how legal and regulatory requirements are being implemented affect the willingness of regulatees to comply, such as the interaction between the regulator and the regulatee, or the experienced fairness of an enforcement decision by an authority (Ayres \& Braithwaite 1992).

A third cluster of motivations considers the impact of descriptive social norms. This part of the literature holds that regulatees conform to a social norm regarding compliance (Deutsch \& Gerald 1955). If they experience that a legal or regulatory requirement is generally complied with, then they will do so too; yet if they experience that it is generally not complied with, then they will not comply with it either (Scholz \& Lubell 1999; Tyran \& Feld 2002).

A fourth cluster of motivations considers how regulatees have internalised compliance. On the one hand, it considers that compliance results from regulatees' perception of law as a source of moral authority (Tyler 1990)-morals in support of the law. Legal and regulatory requirements are considered to shape and strengthen one's moral understanding of what is right and wrong. If such requirements are considered legitimate, this part of the literature argues, compliance will follow. On the other hand, it considers regulatees' general duty to obey (McGraw \& Scholz 1991; Van der Berg 2003): Legal and regulatory requirements are complied with simply because doing so is required.

Closely related to all this, a fifth and final cluster of motivations considers that regulateeswhether aware of it or not-carry out a cost-benefit analysis of their compliance behaviour (Ehrlich 1972): If the benefits of complying outweigh its costs, they will comply; otherwise, they will not (but see Anonymous, 2015b).

What is of specific interest about this part of the literature is that it assumes symmetry: If a motivation is present, then compliance is expected to follow; if it is not present then violation is expected to follow. This assumed compliance-non-compliance dichotomy is however not often empirically scrutinised.

\section{Broad ideal types and (narrow) patterns}

Inspired by these motivations, and understanding that it is unlikely that a single motivation best explains compliance, scholars often develop typologies of compliance motivations when seeking to explain compliance behaviour. These typologies can, broadly, be clustered in two groups. The first group presents broad theoretical 'ideal types'. The types in it are often loosely based on the compliance motivations introduced above (e.g., Braithwaite 2009; Kagan \& Scholtz 1984; Kirchler et al. 2008). A well-known example of the first group is Kagan and Scholtz's (1984) typology, which distinguishes: 'amoral calculators' - firms that only comply when it is in their own economic advantage; 'political citizens' - firms that comply because they agree with the goals of the law or simply because it is the law; and 'organisationally incompetent' - firms that are willing to comply, but fail to do so because they do not know the law or lack the required internal controls. A fourth type was added by Black (1996) - 'irrational non-compliers' - referring to those who do not comply 
because they reject the authority of the law or of those in power. Table 1 gives examples of typologies that fit this group.

\section{TABLE 1 ABOUT HERE}

In the second group, typologies build on a selected number of motivations, and they are often the result of large-n quantitative studies (e.g., Hutter 1997; Lehmann Nielsen \& Parker 2012; May 2004; Tyler 1990). A well-known example of the second group is Lehmann Nielsen and Parker's (2012) study of Australian firms. It applies a cluster analysis to derive a typology of compliance motivations. Building on economic, social and normative motives to comply (abstracted from a larger set of compliance motivations), it arrives at a typology of: 'social citizens' - firms that want to comply and pursue their own economic and societal interests; 'good citizens'-firms that are like the social citizens, but they downplay the priority social motivations to comply and agree less than that group with the substantive goals behind the law; and 'dissenters' - firms that again look very much like the first group, but disagree with the goals of the law. Table 2 gives an overview of a number of other typologies that fit this group.

\section{TABLE 2 ABOUT HERE}

Both groups of typologies have their own strengths - and weaknesses. The first group holds highly inclusive typologies that are (theoretically) applicable to a wide range of settings and often come with appealing terminology. This makes them attractive as a heuristic for scholars and policymakers when assessing compliance. They may, however, be critiqued for lacking methodological rigour and empirical reach (May 2005; Parker \& Nielsen 2009). The analytical step made from the underlying data to the typologies in this set often appears intuitive, rather than systematic. Compliance behaviour is considered 'holistically'; it is not based on a specified (limited) set of motivations - or the interactions between them. Also, the oft small to medium-n database underlying these studies limits the reach of these studies: Whilst the types they present may inspire studies in other contexts, it is unlikely that they have much predictive power for such contexts (cf., Lijphart 1971)

The typologies in the second group build on a predefined set of compliance motivations, and they apply sophisticated statistical analysis techniques to provide a clear link between data and typology. The large-n databases and the methodological rigour add to the empirical reach of such typologies. They may, however, be critiqued for the type of data upon which they rely: (selfreported) survey data, government collected data, and, sometimes, observations. The data reliability of such sources is questioned (Cialdini 2003; Elffers et al. 1987), which negatively affects the validity of the typologies in this second group (May 2005; Parker \& Nielsen 2009). These typologies may also provide an unrealistic view of compliance when the studies underlying them aim to understand which (single) type best explains compliance: The often small number of compliance motivations selected for inclusion in a study (see table 2) runs the risk of resulting in a narrow understanding of compliance behaviour. A typology then may create the illusion that compliance is simply a journey through (a small number of) predetermined or fixed behavioural patterns (e.g., Lee 2008).

Both groups of typologies assume mutual exclusivity: An individual regulatee fits only one compliance type and not another. For typologies in the first group this is often an assumption logically inferred from the data; for the second group this is a result from the method chosen. Like 
the assumed compliance-non-compliance dichotomy identified before this assumed mutual exclusivity is not often empirically scrutinised.

\section{Research design}

As indicated in the introduction, we have selected QCA to analyse our dataset of Chinese farmers' compliance with or violation of pesticide regulation because it is particularly suited to trace patterns of association between interacting conditions (compliance motivations) and the outcome of interest (compliance or non-compliance), whilst relying on in-depth qualitative data. The fundamentals and background of QCA are well explained and documented in a series of textbooks (Ragin 2008; Rihoux \& Ragin 2009; Schneider \& Wagemann 2012) and also in the growing literature on 'two cultures of research' (Berg-Schlosser 2012; Goertz \& Mahony 2012; Moses \& Knutsen 2012). We therefore only focus on the core aspects of QCA that we consider necessary for readers to follow our analysis.

QCA differs from other methods in its focus. 'The key issue [for QCA] is not which variable is the strongest (i.e., has the biggest net effect) but how different conditions combine and whether there is only one combination or several different combinations of conditions (causal recipes) of generating the same outcome' (Ragin 2008, p. 114). ${ }^{1}$ QCA is grounded in set theory, a branch of mathematical logic that allows the study, in detail, of how causal conditions contribute to a particular outcome. A particular strength of QCA is that it can be applied to arrive at evidence-based typologies (cf., Fiss 2011). ${ }^{2}$

QCA has rapidly evolved: Various data analysis techniques are now available under the larger QCA umbrella (Schneider \& Wagemann 2012). We apply crisp set qualitative comparative analysis (csQCA) developed first-a binary technique. More sophisticated techniques are now available that allow the use of more nuanced qualitative differences in data-multi-value and fuzzy set qualitative comparative analysis (mvQCA and fsQCA, see further, Schneider \& Wagemann 2012). When we designed our research in 2011, we chose csQCA for two reasons. First, the outcomes we are interested in are binary: compliance or non-compliance. Second, most of the compliance motivations we are interested are fairly complex as interviewees may experience subtle differences in how they affect them (particularly for the latter three clusters). Because the majority of our interviewees (farmers) have a very basic level of education or none at all we were somewhat concerned they would get lost in too complex questions that allow for teasing out subtle differences. We therefore asked questions that aimed for extensive answers, but also allowed for responses (broadly) along the line of yes/no, a little/much, high/low, legal/illegal, gets punished/gets not punished, and so on. The answers collected were, indeed, often very basic and allowed for binary coding only for most of the motivations studied (for all clusters, but the first).

For those less familiar with QCA, an explanation of the terminology may be helpful. Within QCA, types of interacting conditions (compliance motivations) are referred to as 'paths', and a full typology is referred to as a 'solution'. Whilst QCA uses numerical symbols, it is a qualitative method. The numerical information provided throughout this article is a description of data patterns that

\footnotetext{
${ }^{1}$ Regression analysis may be applied to a similar end; Vis (2012) and Warren et.al. (2013) contrast QCA with regression analysis, highlighting the strengths and weaknesses of both approaches.

${ }^{2}$ Cluster analysis may be applied to a similar end; Cooper and Glaesser (2011) contrast QCA with cluster analysis, highlighting the strengths and weaknesses of both approaches.
} 
underlie the dataset, not simplistic reductions of the qualitative data obtained (cf., Schneider \& Wagemann 2012). A 'consistency score', for instance, indicates how well a path and the full solution reflect the data; a 'coverage score' indicates how much of the data is explained by the paths and solution uncovered.

In QCA, associations between conditions and outcomes are expressed in terms of necessity and sufficiency. Necessity refers to a situation in which the outcome (compliance) cannot be produced without the condition (a compliance motivation): If the outcome is present, the condition is present. Sufficiency refers to a situation in which a condition itself can produce the outcome without the help of other conditions-humans need oxygen to sustain life (oxygen is a necessary condition for human life), but oxygen by itself is not sufficient to sustain life (food and water, for instance, are other necessary conditions). It goes without saying that QCA is not without criticism, and we reflect on problems we have experienced in the concluding section (see also, Emmenegger 2012; Hug 2013; Rihoux \& Marx 2013).

\section{Case selection, data collection}

Through our study, we seek to understand farmers' compliance behaviour with pesticide regulation in China's Hunan province. This province was chosen because it is a typical, traditional agricultural province in China and prior to the study we found no indications of farmer compliance being different in Hunan than in other provinces (Statistical Bureau of Hunan 2012) -that being said, we do not claim that Hunan province is perfectly representative for all agricultural provinces in China.

To gain insight into their compliance behaviour, 101 farmers were interviewed, as well as 31 local experts to assess the validity of the farmer data. To capture the variation in the population of Hunan vegetable farmers, three counties were selected on the basis of vegetable yield and levels of economic development-one high income county producing for provincial markets; one middle income county producing for local county markets; and one low-income county producing for crossprovincial markets. Within these counties, ten villages were selected-evenly distributed amongst the counties-based on accessibility, as well as the type of farms: small individual farms; medium to large cooperative forms of farming; and associated forms of farming. Farms were evenly distributed amongst the different villages. In each village, a sample size of farmers was determined relative to village population and age distribution.

The study is influenced by Winter and May's study of Danish farmers' compliance behaviour (Winter \& May 2001). In contrast to them, however, we did not rely on a survey, but on semistructured interviews with farmers, to overcome, as much as possible, the complications of studying and measuring compliance (cf., Elffers et al. 1987). We asked questions in a dialogue structure, allowing farmers to speak longer and more in-depth on issues of interest to them-including topics that were not necessarily the focus of the study. This allowed us to build trust and gave us time to embed more sensitive questions about compliance within non-sensitive questions about farming practices (Anonymous 2015). A large portion of farmers talked openly about non-compliance-13\% told they violate pesticide type regulation, and $59 \%$ time interval regulation-indicating that they were comfortable enough to do so.

In this article, we focus on two compliance behaviours: compliance with the types of pesticides farmers are allowed to use (O_type), and compliance with the time interval between using pesticides and harvesting crops (O_time). We address compliant and non-compliant behaviour (outcomes). Our focus is on eight compliance motivations (conditions) derived from the current literature: (i) capacity to comply, (ii) legal knowledge, (iii) deterrent effect of sanctions, (iv) cost- 
benefit analysis, (v) descriptive social norms, (vi) morals, (vii) general duty to obey, (viii) procedural justice.

We found that the theoretical model of these eight conditions best explained our data-it resulted in the highest coverage scores-as compared to other models we trialled building on smaller sets of conditions and sets of eight slightly different conditions (cf., Schneider \& Wagemann 2012). Also, whilst the ceiling to the number of conditions that can be included in a csQCA analysis depends on the number of cases studied and the spread of the observations of the conditions selected (Marx \& Dusa, 2011), we followed conventional csQCA practise that argues to limit studies to eight conditions (Rihoux \& Ragin 2009). The number of possible configurations increases exponentially with each condition added (with $k$ conditions the number of possible configurations is $2^{k}$ ), but the number of empirical observations in a study is fixed-in our case compliance behaviour of 101 farmers. Thus, the more conditions added to the explanatory model, the more a QCA analysis relies on counterfactuals. That is, if a researcher decides to rely on counterfactuals from all conditions included-the method leaves it to the researcher to make that choice. In the simplification process of the QCA analyses we only rely on counterfactuals from conditions that, we feel, have been sufficiently studied and documented in the literature to give enough certainty about their impact on compliance and non-compliance-these are the conditions from the first two clusters (in other words, we rely on empirical observations and counterfactuals for capacity to comply, legal knowledge, deterrent effect of sanctions, and procedural justice; and on empirical observations exclusively for general duty to obey, morals, cost-benefit analysis, and descriptive social norms). We return to this issue in the concluding section.

To measure compliance with the types of pesticides, farmers were asked to point out the pesticides they normally use on a chart of common legal and illegal pesticides for the Chinese context. To measure compliance with the time interval rules, we asked how many days there usually are between applying pesticides and harvesting the crops. We then moved to questions about motivations for particular compliance behaviour. To gain insight into the deterrent effect of sanctions, for example, we asked what could happen if someone like them did not comply with legal requirements, and what the severity of a sanction or punishment would be. The answers were coded separately for both compliance behaviours, and for the individual compliance motivations. Online Appendix A further discusses data-coding (table A1) and presents all data scores (the 'raw data'; table $A 2$ and table $A 3)^{3}$

\section{Compliant farmers}

We address compliance with types of pesticides first, followed by compliance with the time interval between pesticide application and harvesting. Following established QCA practice, the data are first analysed for necessary conditions, before they are exposed to more complex analysis to identify (the configurations of) sufficient conditions.

\section{Compliance with type of pesticides}

A test for necessity seeks to understand whether the outcome of interest can only be produced if a specific (combination of) condition(s) is present. Table 3 presents the results of the analysis for necessity.

\footnotetext{
${ }^{3}$ LINK TO ONLINE APPENDIX HERE
} 


\section{TABLE 3 ABOUT HERE}

Conditions should only be considered necessary if their consistency scores are very high (consistency indicates how strongly the condition relates to the outcome); a cut-off point of 0.90 is advised (Rihoux \& Ragin 2009, p. 45). Table 3 points to three such conditions: cost-benefit analysis, descriptive social norms, and morals. The relatively high coverage scores of these conditions indicate that they are likely necessary conditions for causing this outcome (coverage indicates how relevant the condition is for achieving the outcome). It is, of course, of interest to further understand whether these three necessary conditions combine with each other or with the other conditions for compliant famers (conjunctural causation), and whether a single combination of conditions or different combinations of conditions are related to compliant behaviour (equifinality). This is what we seek to understand by applying an analysis for sufficient conditions.

To gain insight into the issues of equifinality and conjunctural causation, the data are analysed aiming to logically reduce the empirically observed configurations (Rihoux \& Ragin 2009, Chapter 5, box 8.1; Schneider \& Wagemann 2012, Chapter 11). A first step of this analysis is to create a truth table, which is represented in Table 4.

\section{TABLE 4 ABOUT HERE}

The truth table represents all configurations of conditions that are logically possible. With the eight conditions included in our study, the number of logically possible combinations is $256-$ $2^{\wedge} 8$. All 101 empirical observations (the farmers) are included in this table (rows 1 to 29)-each observation is unpacked as a configuration of conditions. Some configurations were observed for more than one farmer (e.g., row 1) -the number of observations per configuration (frequency) is indicated table 3 . The truth table also includes possible configurations, but without empirical observations - the logical remainders in rows 30-256.

The truth table is used for a logical minimisation of the data. Following Ragin (2008), only configurations with at least two observations are considered in the analysis, because of the relatively large datasets (also, Schneider \& Wagemann 2012). ${ }^{4}$ From here on, a standard analysis is carried out in FS/QCA 2.5 (Ragin \& Davey 2014). Table 5 represents the intermediate solution that results from this analysis. An intermediate solution includes counterfactuals in the minimisation process -we only use counterfactuals from the first two clusters of motivations, and rely on empirical observations exclusively for the other motivations (see research design).

\section{TABLE 5 ABOUT HERE}

Table 5 adopts a straightforward notation and presentation of causal configurations ('paths') that are sufficient to cause the outcome of interest. It indicates that two paths are related to compliant behaviour with the type of pesticides. The solution coverage (0.91) may be considered as high (Ragin 2008), and it indicates that the solution strongly relates to the outcome observed (see further, Schneider \& Wagemann 2012, section 5.3). The solution consistency (1.00) is high as well,

\footnotetext{
${ }^{4}$ We have carried out analyses with higher cut-off points. Whilst this resulted in simpler solutions, we felt they were too simple to explain our data. Textbooks indeed warn researchers not to blindly apply the computer software and the solutions it produces. Whilst less complex solutions might have intuitive appeal, they in fact are less precise in explaining the data (cf., Rihoux \& Ragin 2009; Schneider \& Wagemann 2012).
} 
and it indicates that the solution is of high empirical importance in reaching the outcome. The two paths can be considered as two causal recipes that are individually sufficient to cause the outcome. Interestingly, all three necessary conditions combine in both paths, which means that we can also formulate the full solution as:

Outcome O_type $\rightarrow$ mora*socn*cba* $\left\{\begin{array}{l}\text { gdto } \\ + \\ \text { lega*dete }\end{array}\right.$

In this formula, the multiply symbol ('*') represents the logical AND, and the sum symbol ('+') represents the logical OR. The above formula (1) can be read as: compliance with the regulation prescribing the type of pesticides farmers are allowed to use is found in farmers who report:

- law as a source of moral authority, and descriptive social norms to comply, and a positive cost benefit analysis, and a general duty to obey (path O_type.1); or,

- law as a source of moral authority, and descriptive social norms to comply, and a positive cost benefit analysis, and legal knowledge, and a deterrent effect of sanctions (path O_type.2).

Table 5 indicates the farmers that fit each path: 67 farmers fit path O_type.1; 66 farmers fit path ${ }_{\text {_ }}$ type.2; and 7 farmers indicate compliant behaviour, but do not fit either of these paths. Table 5 further indicates that 52 farmers fit both paths, confirming the idea that the analysis for sufficient conditions results in ideal types that explain compliant behaviour, and that farmers can empirically meet different ideal types (cf., Fiss 2011) - especially when the ideal types are fairly similar, which is the case in this part of our study.

\section{Compliance with time interval between pesticide application and harvesting}

Again, the data are analysed for necessary conditions before they are subjected to the more complex analysis for sufficient conditions. To prevent too much repetition in this article, we only present the outcomes of the analyses for necessary and sufficient conditions in what follows, as well as the simplified formulae. Additional data, particularly the truth tables underlying these analyses, are presented in Online Appendix B. Table 6 presents the results of the analysis for necessity, and table 7 shows the results of the analysis for sufficiency.

\section{TABLE 6 ABOUT HERE}

\section{TABLE 7 ABOUT HERE}

Table 6 indicates the likely necessary conditions for compliance with pesticide regulation: cost-benefit analysis, descriptive social norms, and morals. Table 7 indicates that three paths are related to this compliant behaviour (the solution coverage and consistency for the full solution are high), which can be simplified as: 
Outcome O_time $\rightarrow$ mora*cba*lega*capa* gdto + mora*socn*cba* $\left\{\begin{array}{l}\text { gdto } \\ + \\ \text { lega }\end{array}\right.$

The above formula (2) can be read as: compliance with the regulation prescribing the time interval between applying pesticides and harvesting crops of pesticides is found in farmers who report:

- law as a source of moral authority, and a positive cost benefit analysis, and legal knowledge, and a capacity to comply, and not a general duty to obey (path O_time.3); or,

- law as a source of moral authority, and descriptive social norms to comply, and a positive cost benefit analysis, and a general duty to obey (path O_time.1); or,

- law as a source of moral authority, and descriptive social norms to comply, and a positive cost benefit analysis, and legal knowledge (path O_time.2).

\section{Non-compliant farmers}

The literature often implicitly understands non-compliant behaviour as the inverse of compliant behaviour. After interviewing 101 farmers and roughly analysing our data through a systematic coding practice, we felt that the assumption that 'compliance is the inverse of non-compliance' might be too simplistic. Following this theory and data-informed 'hunch' (cf., Kahneman 2011; Layder 2006), we decided to subject our data on non-compliance to a csQCA analysis as well, seeking to understand whether the motivations mentioned by compliant farmers were the inverse of motivations mentioned by non-compliant farmers. For instance, the presence of three conditions (law as a source of moral authority, descriptive social norms to comply, and a positive cost benefit analysis) were found in most paths in section 4, and we wondered whether they were absent (the inverse of present) for farmers that reported non-compliant behaviour. In QCA the ' ' symbol is used to indicate 'inverse'. In this section, we follow the same analytical techniques and choices made in section 4.

\section{Non-compliance with types of pesticides}

Table 8 presents the results of the analysis for necessary conditions, and table 9 shows the results of the analysis for sufficient conditions.

\section{TABLE 8 ABOUT HERE}

TABLE 9 ABOUT HERE

From table 8, it becomes clear that four conditions may be necessary for non-compliance: the absence of a deterrent effect of sanctions, a non-positive cost-benefit analysis, the absence of (experienced) descriptive social norms, and the absence of (an experience of) the morals. The relatively low coverage scores of the absence of a deterrent effect of sanctions and a non-positive cost-benefit analysis may indicate that they are trivial necessary conditions (Schneider \& Wagemann 2012). 
Table 9 indicates that two paths are related to non-compliant behaviour with the type of pesticides. The solution coverage (0.62) may be considered as modest (Ragin 2008), and it indicates that the solution leaves a part of the observed outcome unexplained - i.e., the solution only explains the behaviour of seven out of thirteen famers who reported non-compliant behaviour. The solution consistency (1.00) can be considered as high, but it is of less relevance here, because the solution coverage is only modest (Schneider \& Wagemann 2012). Whilst the two paths are both fairly complex (including five conditions), they can be further reduced in the following formula:

Outcome $\sim$ O_type $->\sim$ mora ${ }^{* \sim}$ socn $* \sim$ cba ${ }^{* \sim}$ dete ${ }^{* \sim \text { proj }}\left\{\begin{array}{l}\sim \text { capa } \\ + \\ \sim \text { gdto }\end{array}\right.$

The above formula (3) can be read as: non-compliance with the regulation prescribing the type of pesticides farmers are allowed to use is found in farmers who report:

- the absence of morals in favour of compliance, and the absence of (experienced) descriptive social norms, and a non-positive cost-benefit analysis, and the absence of a deterrent effect of sanctions, and an absence of (experienced) procedural justice, and a lack of capacity to comply (path O_type.1); or,

- the absence of morals in favour of compliance, and the absence of (experienced) descriptive social norms, and a non-positive cost-benefit analysis, and the absence of a deterrent effect of sanctions, and an absence of (experienced) procedural justice, and a lack of a(n experienced) general duty to obey the law ( path O_type.2).

What is of interest here is that the absence of a deterrent effect of sanctions is a necessary condition for non-compliance. In other words, this particular condition plays out differently for compliance and non-compliance: There appears to be an asymmetrical relation between the presence/absence of this condition and compliance/non-compliance. The other necessary conditions (morals, descriptive social norms, cost-benefit analysis) do appear to have a symmetrical relation with compliance.

\section{Non-compliance with time interval between pesticide application and harvesting}

Table 10 presents the results of the analysis for necessary conditions, and table 11 shows the results for sufficient conditions.

\section{TABLE 10 ABOUT HERE}

\section{TABLE 11 ABOUT HERE}

From table 10, it becomes clear that four conditions may be necessary for non-compliance: the absence of a deterrent effect of sanctions, a non-positive cost-benefit analysis, the absence of (experienced) descriptive social norms, and the absence of (an experience of) procedural justice. The relatively low coverage scores of the absence of a deterrent effect of sanctions and the absence of (an experience of) procedural justice may indicate that they are trivial necessary conditions. 
Table 11 indicates that three paths are related to compliant behaviour with the type of pesticides (the solution coverage and consistency for the full solution are high), which can be simplified as:

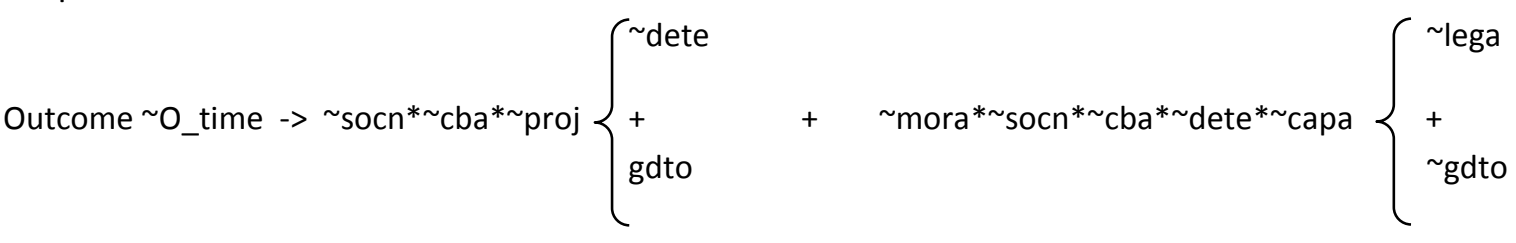

The above formula (4) can be read as: non-compliance with the regulation prescribing the time interval between applying pesticides and harvesting crops of pesticides is found in farmers who report:

- the absence of (experienced) descriptive social norms, and a non-positive cost-benefit analysis, and a lack of capacity to comply, and a lack of (an experience of) procedural justice, and the absence of a deterrent effect of sanctions (path O_time.3); or,

- the absence of (experienced) descriptive social norms, and a non-positive cost-benefit analysis, and a lack of capacity to comply, and a lack of (an experience of) procedural justice, and a general duty to obey the law (path $\sim O_{-}$time.4); or,

- the absence of morals in favour of compliance, and the absence of (experienced) descriptive social norms, and a non-positive cost-benefit analysis, and the absence of a deterrent effect of sanctions, and a lack of capacity to comply, and a lack of legal knowledge (path O_time.1); or,

- the absence of morals in favour of compliance, and the absence of (experienced) descriptive social norms, and a non-positive cost-benefit analysis, and the absence of a deterrent effect of sanctions, and a lack of capacity to comply, and a lack of a(n experienced) general duty to obey the law ( path O_time.2).

\section{Discussion and conclusion}

The above analyses have indicated that compliance motivations interact in compliant and noncompliant behaviour (conjunctural causation) and that different configurations of compliance motivations can result in compliant and non-compliant behaviour (equifinality)-at least for the behaviour of the 101 farmers interviewed. That equifinality and conjunctural causation are at play is, however, the least interesting of our findings: Because csQCA is developed to better understand equifinality and conjunctural causation, among other things, this likely is 'uncovered' when suitable data are subjected to the analyses for necessity and sufficiency-all the more when the data are collected based on claims and empirical findings in support of (assumed) equifinality and conjunctural causation (as was the case for our study).

What is of more interest is that the analyses for sufficiency point out a limited number of paths that explain the two compliance behaviours we have studied in our pool of 101 farmers. We only find two paths for compliance with the type of pesticides farmers are allowed to use, and only three paths for compliance with the time interval between applying pesticides and harvesting crops. Keeping in mind that, for each of the two compliance behaviours, 256 paths are logically possible with the eight motivations we focus on, this truly is a considerable simplification. Yet again, this empirical finding is particularly a result of the method chosen. Our study does also point to a number of insights that contribute to theorizing on compliance behaviour and compliance 
motivations. We discuss these in what follows. Yet, because these insights should be understood in light of the limitations (and opportunities) that come with the method applied, we discuss those first.

\section{Observations on the method applied: Opportunities and limitations}

In applying csQCA we experience a number of advantages: It helps to highlight equifinality and conjunctural causation of interacting compliance motivations, it allows us to study compliance and non-compliance, it provides a systematic approach to move from data to findings, and it allows the use of data on compliance motivations obtained through in-depth interviews. We are further positive about how it helps to get grip on this (qualitative) data: The tables presenting the analyses for sufficient conditions help to identify typical and atypical cases and patterns (Ragin \& Becker 1992; Yin 2003). Table 5, for example, identifies the 'typical' farmers that fit the two compliance types, as well as the seven 'atypical' farmers that do not fit them - the 'unexplained cases'. It further helps to identify the 51 farmers that fit both types, and the famers that fit one type uniquely. In particular, the identification of 'atypical' farmers is of interest, because these specific farmers do not fully fit the theoretical model used-the eight compliance motivations. A better understanding of their behaviour might help to enrich the compliance literature further, and a logical next step of our study is to focus uniquely on them (cf., Layder 2006).

That being said in praise of csQCA for compliance studies, the method also comes with specific complications, and these should not be taken lightly. First, by following a highly systematic approach to data analysis, csQCA challenges scholars to move beyond intuitive interpretations. The downside, of course, is that the paths related to compliance that we have presented here are fairly difficult to read, and we expect that they will be all the more so for a non-academic audience, such as policymakers and practitioners. We did not experience the risk of slavishly applying the method to 'mine' data, but we agree with the literature that this risk exists-perhaps we were in the fortunate position that we could use data we know very well because we collected it ourselves (for further published critiques of QCA see, Emmenegger 2012; Hug 2013; Rihoux \& Marx 2013).

More problematic is the reliance on counterfactuals - albeit this is a general critique of QCA (Emmenegger 2012). In our study, we built on eight compliance conditions. Together, they allow for 256 possible configurations $-2^{\wedge} 8$. However, our data identified much smaller sets of empirically observed configurations - only 29 for compliance with type of pesticides. We felt comfortable enough with the literature on the first two clusters of compliance motivations to rely on counterfactuals (capacity to comply, legal knowledge, deterrence effect of sanction, and procedural justice), but not with the literature on the last three clusters (descriptive social norms, morals, general duty to obey, cost-benefit analysis, see further Anonymous 2015b). For the latter we have relied on empirical observations uniquely-QCA allows researchers, after all, also to not rely on counterfactuals if they are concerned about these (see also research design). ${ }^{5}$ Whilst relying on counterfactual is a conventional approach in QCA-and for many other data analysis techniques-it also implies that the findings from our study are strongly influenced by assumptions in the compliance literature (but only for those motivations we use as counterfactuals).

\section{Theoretical contribution}

\footnotetext{
${ }^{5}$ We are in depth to both reviewers for challenging us to critically think about and reflect on the use of counterfactuals in this study.
} 
Our study has implications for assessing the value of typologies discussed above. First, all of the paths (types) we identified are fairly complex, including, at the very least, four different compliance motivations. For the typologies building on large-n studies - characterised as '(narrow) patterns' this supports existing critique that they may include too small a number of explanatory variables (compliance motivations) to provide an adequate insight into what explains compliance in real world settings (also, May 2005; Parker \& Nielsen 2009) - but again, the number of motivations we relied on (eight) comes with its own methodological complications (see above).

The group of typologies characterised as 'ideal types' appear more problematic. The various paths related to compliance identified in our study can be understood as evidence-based ideal types (Fiss, 2011), but none of them can be easily captured in catchy sound bites such as the ideal types illustrated in table 1. We do not argue against these sound bites, but against the often unexplained inferential step from data to types in these studies. Without a systematic approach to data analysis, small-n studies may become subject to a desire to present overly stylised typologies (also, May 2005; Parker \& Nielsen 2009). The problem with such typologies becomes clear, for instance, if we contrast our two paths for compliant behaviour with pesticide types (path O_type.1, resembling 67 farmers; and path O_type.2, resembling 61 farmers) with Kircher et al.'s (2008) well-known slippery slope model (see Figure 1). These two paths resemble two types in that model: voluntary compliance and enforced compliance. These two terms indicate mutually exclusive types-and one would assume from them that regulatees either fit the 'voluntary' or the 'enforced' type. However, in our study, we found that 52 farmers fit both types-indicating equifinality at the individual regulatee level.

Our study has implications also for thinking about compliance and non-compliance more generally. We find considerable similarities and relevant differences in the paths related to compliant behaviour (O_type and O_time) and non-compliant behaviour ( O_type and O_time). In terms of similarity: the presence of the combination of mora*socn*cba (law as a source of moral authority, and descriptive social norms to comply, and a positive cost benefit analysis) in four of the five paths uncovered for compliant behaviour (all but $O_{-}$time.3) is mirrored by the combination of mora* socn* cba (the absence of morals in favour of compliance, and the absence of descriptive social norms, and a non-positive cost-benefit analysis) in four of the six paths uncovered for noncompliant behaviour (all but $\sim O_{-}$time. 3 and $\sim O_{-}$time.4). This indicates that this cluster of conditions can be considered as symmetrical in affecting compliance and non-compliance within the pool of farmers studied. This symmetrical relationship between compliance and non-compliance is assumed in the literature, but is not often empirically observed.

However, our data also point to a non-symmetrical relation between the deterrent effect of sanctions and compliance. The analyses of necessary conditions pointed out that (experienced) deterrence is not a necessary condition for compliance, but that the absence of (experienced) deterrence is a necessary condition for non-compliance (all paths, but $\sim O_{-}$time.4). Our data further indicate that deterrence (as part of a set of compliance conditions) does play a marginal role in affecting compliance (in one path for one compliance behaviour), the absence of deterrence does, however, play a considerable role in affecting non-compliance (in five out of six paths for both noncompliance behaviours). This finding challenges our thinking about the assumed compliance-noncompliance dichotomy in the literature-it indicates that compliance is not necessarily the inverse of non-compliance.

Whilst it may seem counterintuitive that compliant and non-compliant behaviour are not different sides of the same (motivational) coin, there is a (theoretical) explanation. Building on our study, we argue that, in compliance decision making, deterrence plays a different role than in 
violation decision making. Decision making, we feel, is key here. Deciding to comply is not the same as (also) deciding 'not to violate' - if we decide to stick to speed limits, we likely do not (also) decide to not hit the pedal to the metal (building on insights from behavioural economics, cf., Kahneman 2011). What we observe is not a reassurance and reminder function for compliant decision making from deterrence, but the lack of deterrence as a reminder and reassurance that violation goes unnoticed or unpunished (terminology from: Thornton et al. 2005)-or less prosaic, perhaps compliance simply is a habit for most of the farmers interviewed (cf., Duhigg 2012). This reasoning is in line with lan Ayres and John Braithwaite's (1992) responsive regulation model, which assumes that most compliance will occur without active deterrence. Indeed, those complying, the large majority of farmers interviewed, do not mention the presence of deterrence as a necessary condition of their behaviour - they sit at the base of the responsive regulation pyramid.

This allows us to hypothesise that compliance and non-compliance are affected symmetrically only by specific motivations - but this hypothesis needs further testing to assess if it also holds for regulatees and in contexts other than in our study. Scholars may wish to fine tune their compliance studies by including this focus on motivations that affect compliance and violation symmetrically and non-symmetrically. A better understanding of such asymmetry may have important consequences for law enforcement: It may explain why in situations of non-compliance choosing the opposite enforcement and disciplining strategy (from the one in place) is no guarantee of improved compliance.

To conclude, whilst acknowledging the limitations of $\operatorname{csQCA}$, we feel it provides a valuable method to systematically analyse a large qualitative data set such as ours. It allowed us to critically scrutinize existing typologies of compliance motivations, and to empirically illustrate symmetry and asymmetry between compliance motivations and compliance behaviours (at least for our data set). We know of no other methods that allow for doing so with the relative ease of csQCA, and we expect that the available more sophisticated QCA techniques (mvQCA and fsQCA) assist scholars in gaining more nuanced understandings of what motivates compliance, how, and where. In sum, despite its methodological shortcomings we hope that our experience with (cs)QCA reported here inspires other scholars to apply it in future compliance studies.

\section{Acknowledgements}

Van der Heijden's contribution to this research was made possible through a generous VENI grant from the Netherlands Organization for Scientific Research. Van Rooij's contribution was made possible through another VENI grant. The authors thank the reviewers and editors of the journal for helpful comments to earlier versions of this article. 


\section{Tables}

Table 1 -Some well-known typologies resulting from small-n compliance studies

\begin{tabular}{|c|c|c|c|}
\hline Author (s) & $\begin{array}{l}\text { Specific } \\
\text { regulatory } \\
\text { context }\end{array}$ & Ideal types involved & Brief descriptions \\
\hline Kagan \& & General & Amoral calculation & Motivated by profit-seeking \\
\hline $\begin{array}{l}\text { Scholz } \\
(1984)\end{array}$ & $\begin{array}{l}\text { corporate } \\
\text { regulation }\end{array}$ & $\begin{array}{l}\text { Principled } \\
\text { agreement }\end{array}$ & $\begin{array}{l}\text { Motivated by belief in the rule of law or long- } \\
\text { term interests }\end{array}$ \\
\hline & & Competence & $\begin{array}{l}\text { Restricted by the competence of the regulated } \\
\text { entity }\end{array}$ \\
\hline \multirow{5}{*}{$\begin{array}{l}\text { Braithwaite } \\
\text { (2009) }\end{array}$} & Tax regulation & Commitment & Motivated by moral obligation \\
\hline & & Capitulation & $\begin{array}{l}\text { Motivated by an acceptance of the authority as } \\
\text { a legitimate power to pursue the collective's } \\
\text { goals }\end{array}$ \\
\hline & & Resistance & Motivated by doubts about the authority \\
\hline & & Disengagement & $\begin{array}{l}\text { Motivated by ignorance of the authority and the } \\
\text { law }\end{array}$ \\
\hline & & Game playing & $\begin{array}{l}\text { Motivated by seeking possibilities to increase } \\
\text { the regulated entities' own interests }\end{array}$ \\
\hline \multirow[t]{4}{*}{$\begin{array}{l}\text { Kirchler } \\
\text { (2008) }\end{array}$} & Tax regulation & $\begin{array}{l}\text { Voluntary } \\
\text { compliance }\end{array}$ & Motivated by high trust of the authority \\
\hline & & $\begin{array}{l}\text { Enforced } \\
\text { compliance }\end{array}$ & $\begin{array}{l}\text { Motivated by low trust of the authority, but } \\
\text { strong power of the authority to effectively } \\
\text { audit and sanction non-compliant behaviour }\end{array}$ \\
\hline & & Tax avoidance & $\begin{array}{l}\text { Motivated by intention to reduce taxes within } \\
\text { the legal range of the law but deterred from } \\
\text { illegal reductions }\end{array}$ \\
\hline & & Tax evasion & $\begin{array}{l}\text { Motivated by both low trust in authority and } \\
\text { low power of the authority }\end{array}$ \\
\hline
\end{tabular}


Table 2 -Some well-known large-n compliance studies

\begin{tabular}{|c|c|c|c|c|c|c|c|c|}
\hline \multirow[t]{2}{*}{ Author (s) } & \multirow[t]{2}{*}{ Specific regulatory context } & \multicolumn{7}{|c|}{ Compliance conditions studied } \\
\hline & & $A$ & B & $\mathrm{C}$ & $\mathrm{D}$ & $\mathrm{E}$ & $\mathrm{F}$ & G \\
\hline Tyler (1990) & General regulation & & & $x$ & & $x$ & $x$ & $x$ \\
\hline Hutter (1997) & $\begin{array}{l}\text { Occupational health and safety } \\
\text { (England and Wales) }\end{array}$ & & & $x$ & & $x$ & $x$ & \\
\hline Winter \& May (2001) & Agro-environmental (Denmark) & $x$ & $x$ & $x$ & & & $x$ & \\
\hline May (2004) & Building safety (United States) & $x$ & $x$ & $x$ & & $x$ & $x$ & \\
\hline $\begin{array}{l}\text { Paternoster \& Simpson } \\
\text { (1993) }\end{array}$ & Corporate regulatory context & & & $x$ & $x$ & $x$ & $x$ & \\
\hline Thornton et al.(2005) & $\begin{array}{l}\text { Corporate environmental regulation } \\
\text { (United States, Canada, Australia and } \\
\text { New Zealand) }\end{array}$ & & & $x$ & $x$ & & $x$ & \\
\hline $\begin{array}{l}\text { Nielsen \& Parker } \\
\text { (2012) }\end{array}$ & Corporate compliance (Australia) & $x$ & & $x$ & $x$ & $x$ & $x$ & $x$ \\
\hline
\end{tabular}

Note: $A$ = ability to obey the law; $B=$ legal knowledge; $C=$ deterrent effect of sanctions; $D=$ descriptive social norms; $E$ = morals; $F=$ general duty to obey; $G$ = procedural justice - see further section 2.2.

Table 3-Necessary conditions outcome O_type

\begin{tabular}{l|c|c}
\hline Condition & Consistency & Coverage \\
\hline Capacity to comply (capa) & 0.35 & 0.86 \\
\hline Legal knowledge (lega) & $0.90^{*}$ & 0.86 \\
\hline Deterrent effect of sanctions (dete) & 0.82 & 0.99 \\
\hline Cost-benefit analysis (cba) & $\mathbf{0 . 9 3}$ & 1.00 \\
\hline Descriptive social norms (socn) & $\mathbf{0 . 9 7}$ & 1.00 \\
\hline Morals (mora) & $\mathbf{1 . 0 0}$ & 0.99 \\
\hline Duty to obey (gdto) & 0.76 & 0.91 \\
\hline Procedural justice (proj) & 0.08 & 0.79 \\
\hline
\end{tabular}

*after rounding; without rounding the value is 0.897727 
Table 4 - Truth table for outcome O_type

\begin{tabular}{|c|c|c|c|c|c|c|c|c|c|c|}
\hline \multirow[t]{2}{*}{ Row } & \multicolumn{8}{|c|}{ Conditions } & \multirow[t]{2}{*}{ Freq. } & \multirow{2}{*}{$\begin{array}{c}\text { O_ }_{-} \\
\text {Type }\end{array}$} \\
\hline & capa & lega & dete & $c b a$ & socn & mora & gdto & proj & & \\
\hline 1 & 0 & 1 & 1 & 1 & 1 & 1 & 1 & 0 & 25 & 1 \\
\hline 2 & 1 & 1 & 1 & 1 & 1 & 1 & 1 & 0 & 21 & 1 \\
\hline 3 & 0 & 1 & 1 & 1 & 1 & 1 & 0 & 0 & 12 & 1 \\
\hline 4 & 0 & 1 & 0 & 1 & 1 & 1 & 1 & 0 & 5 & 1 \\
\hline 5 & 0 & 0 & 0 & 1 & 1 & 1 & 1 & 0 & 4 & 1 \\
\hline 6 & 0 & 1 & 1 & 1 & 1 & 1 & 1 & 1 & 3 & 1 \\
\hline 7 & 1 & 1 & 0 & 1 & 1 & 1 & 1 & 0 & 3 & 1 \\
\hline 8 & 1 & 1 & 1 & 1 & 1 & 1 & 0 & 0 & 2 & 1 \\
\hline 9 & 1 & 1 & 1 & 1 & 1 & 1 & 0 & 1 & 2 & 1 \\
\hline 10 & 0 & 0 & 0 & 0 & 1 & 1 & 0 & 0 & 1 & 1 \\
\hline 11 & 0 & 0 & 1 & 0 & 1 & 1 & 0 & 0 & 1 & 1 \\
\hline 12 & 0 & 0 & 1 & 0 & 1 & 1 & 1 & 0 & 1 & 1 \\
\hline 13 & 0 & 0 & 1 & 1 & 1 & 1 & 0 & 0 & 1 & 1 \\
\hline 14 & 0 & 0 & 1 & 1 & 1 & 1 & 1 & 0 & 1 & 1 \\
\hline 15 & 0 & 1 & 0 & 0 & 1 & 1 & 1 & 0 & 1 & 1 \\
\hline 16 & 0 & 1 & 1 & 0 & 1 & 1 & 1 & 0 & 1 & 1 \\
\hline 17 & 0 & 1 & 1 & 1 & 1 & 1 & 0 & 1 & 1 & 1 \\
\hline 18 & 1 & 1 & 0 & 1 & 0 & 1 & 0 & 0 & 1 & 1 \\
\hline 19 & 1 & 1 & 1 & 0 & 0 & 1 & 1 & 0 & 1 & 1 \\
\hline 20 & 1 & 1 & 1 & 1 & 1 & 1 & 1 & 1 & 1 & 1 \\
\hline 21 & 0 & 1 & 0 & 0 & 0 & 0 & 1 & 0 & 3 & 0 \\
\hline 22 & 0 & 1 & 0 & 0 & 0 & 0 & 0 & 0 & 2 & 0 \\
\hline 23 & 1 & 1 & 0 & 0 & 0 & 0 & 0 & 0 & 2 & 0 \\
\hline 24 & 0 & 0 & 0 & 0 & 0 & 0 & 1 & 0 & 1 & 0 \\
\hline 25 & 0 & 1 & 0 & 0 & 0 & 0 & 0 & 1 & 1 & 0 \\
\hline 26 & 0 & 1 & 0 & 0 & 0 & 1 & 0 & 1 & 1 & 0 \\
\hline 27 & 1 & 1 & 0 & 0 & 0 & 0 & 1 & 0 & 1 & 0 \\
\hline 28 & 1 & 1 & 0 & 0 & 0 & 0 & 1 & 1 & 1 & 0 \\
\hline 29 & 1 & 1 & 1 & 0 & 0 & 0 & 1 & 0 & 1 & 0 \\
\hline \multicolumn{9}{|c|}{ Rows 30 - 256: logical remainders } & 227 & $?$ \\
\hline
\end{tabular}

Abbreviations: capa=capacity to comply; lega=legal knowledge; dete=deterrent effect of sanctions; cba=costbenefit analysis; socn=descriptive social norms; mora=morals; gdto=general duty to obey; proj=procedural justice; Freq.=frequency 
Table 5 - Intermediate solution outcome O_type

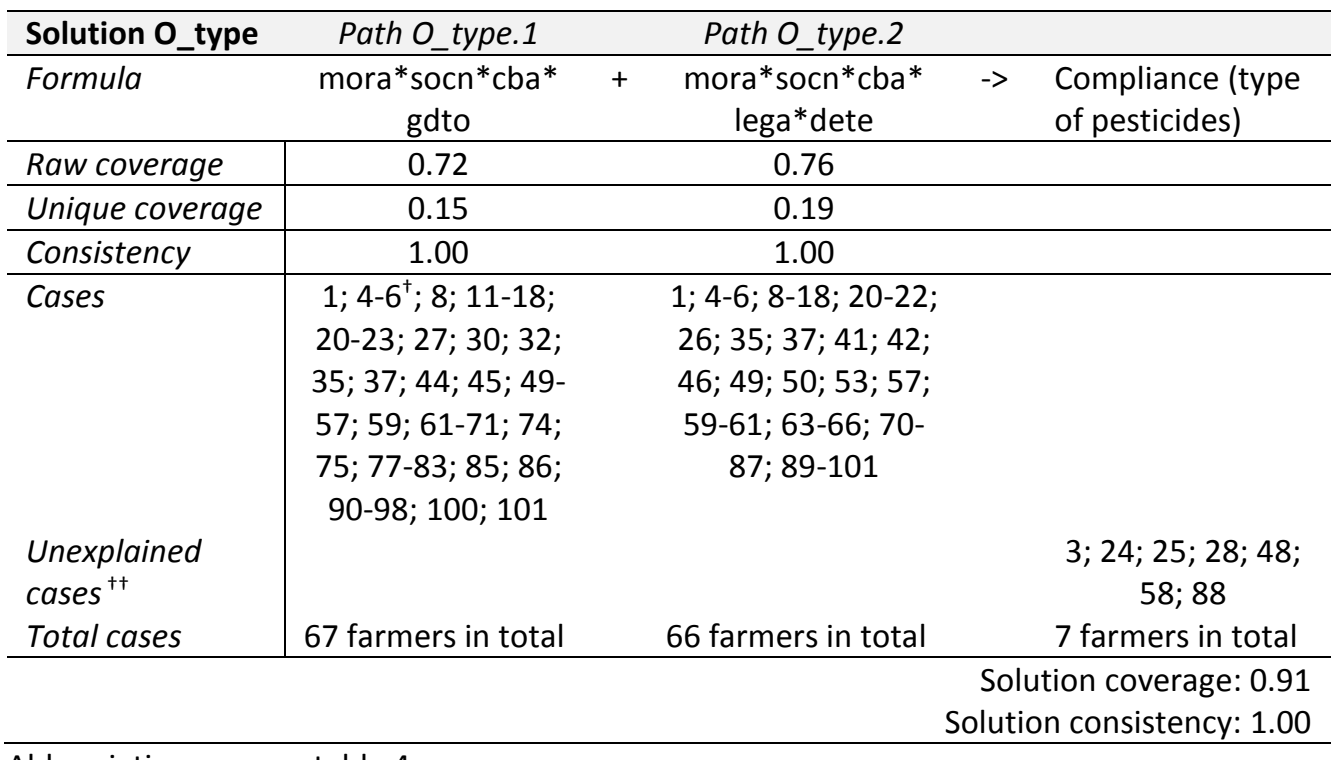

Abbreviations: as per table 4.

'Please note, we only use the '-' symbol to reduce space; not to indicate any relationship between these farmers (but for the fact that they fit the specific path).

${ }^{++}$Farmers that do show compliance, but that do not fit either of the two paths identified.

Table 6-Necessary conditions outcome O_time

\begin{tabular}{l|c|c}
\hline Condition & Consistency & Coverage \\
\hline Capacity to comply (capa) & 0.41 & 0.47 \\
\hline Legal knowledge (lega) & 0.75 & 0.52 \\
\hline Deterrent effect of sanctions (dete) & 0.27 & 1.00 \\
\hline Cost-benefit analysis (cba) & $\mathbf{1 . 0 0}$ & 1.00 \\
\hline Descriptive social norms (socn) & $\mathbf{0 . 9 5}$ & 0.98 \\
\hline Morals (mora) & $\mathbf{1 . 0 0}$ & 0.62 \\
\hline Duty to obey (gdto) & 0.68 & 0.38 \\
\hline Procedural justice (proj) & 0.12 & 0.50 \\
\hline
\end{tabular}


Table 7-Intermediate solution outcome O_time

\begin{tabular}{|c|c|c|c|c|c|c|}
\hline Solution 0_time & Path O_time.1 & & Path O_time.2 & Path O_time.3 & & \\
\hline Formula & $\begin{array}{l}\text { mora*socn*cba* } \\
\text { gdto }\end{array}$ & + & $\begin{array}{l}\text { mora*socn*cba* } \\
\text { lega }\end{array}$ & + mora*cba*lega*capa & $\rightarrow$ & $\begin{array}{l}\text { Compliance } \\
\text { (time interval) }\end{array}$ \\
\hline Raw coverage & 0.68 & & 0.71 & 0.37 & & \\
\hline Unique coverage & 0.24 & & 0.17 & 0.05 & & \\
\hline Consistency & 1.00 & & 1.00 & 1.00 & & \\
\hline Cases & $\begin{array}{c}7 ; 15 ; 27 ; 28 ; 32 ; \\
35 ; 37 ; 44 ; 47 ; \\
49-52 ; 54 ; 56 ; 57 \\
62 ; 65-69 ; 85 ; 96- \\
98 ; 100 ; 101\end{array}$ & & $\begin{array}{c}9 ; 10 ; 25 ; 26 ; 33 ; \\
35 ; 37 ; 44 ; 46 ; \\
47 ; 49-51 ; 53 ; 55 ; \\
56 ; 60 ; 62 ; 62 ; \\
66-68 ; 96-101\end{array}$ & $\begin{array}{l}2 ; 7 ; 9 ; 10 ; 25 ; 38 ; \\
47 ; 49 ; 68 ; 96-101\end{array}$ & & \\
\hline Unexplained cases & & & & & & $\begin{array}{l}\text { No unexplained } \\
\text { cases }\end{array}$ \\
\hline Total cases & $\begin{array}{l}28 \text { farmers in } \\
\text { total }\end{array}$ & & $\begin{array}{l}27 \text { farmers in } \\
\text { total }\end{array}$ & 15 farmers in total & & \\
\hline \multicolumn{7}{|c|}{$\begin{array}{r}\text { Solution coverage: } 1.00 \\
\text { Solution consistency: } 1.00\end{array}$} \\
\hline
\end{tabular}

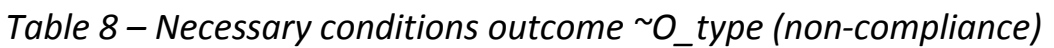

\begin{tabular}{l|c|c}
\hline Condition & Consistency & Coverage \\
\hline$\sim$ Capacity to comply (capa) & 0.62 & 0.12 \\
\hline$\sim$ Legal knowledge (lega) & 0.08 & 0.10 \\
\hline$\sim$ Deterrent effect of sanctions (dete) & $\mathbf{0 . 9 2}$ & 0.44 \\
\hline$\sim$ Cost-benefit analysis (cba) & $\mathbf{1 . 0 0}$ & 0.68 \\
\hline$\sim$ Descriptive social norms (socn) & $\mathbf{1 . 0 0}$ & 0.87 \\
\hline$\sim$ Morals (mora) & $\mathbf{0 . 9 2}$ & 1.00 \\
\hline$\sim$ Duty to obey (gdto) & 0.46 & 0.22 \\
\hline$\sim$ Procedural justice (proj) & 0.77 & 0.11 \\
\hline
\end{tabular}

The symbol ${ }^{\prime} \sim$ indicates the absence of the condition.

Table 9-Intermediate solution outcome $\sim O_{-}$type (non-compliance)

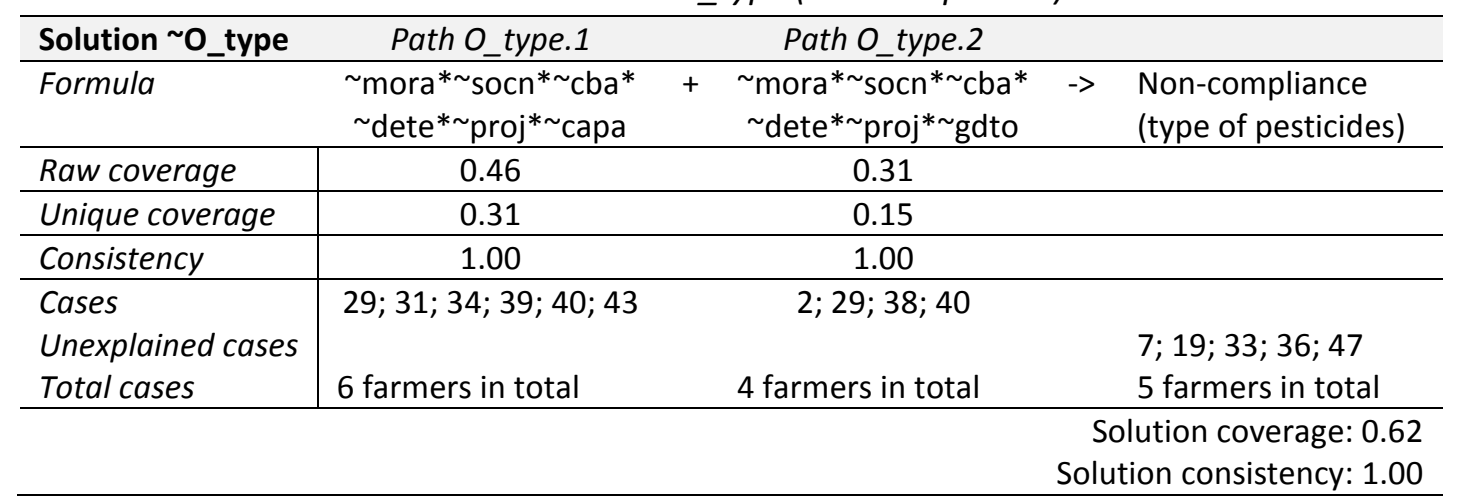

Abbreviations: as per table 4

The symbol ' $\sim$ ' indicates the absence of the condition. 
Table 10 - Necessary conditions outcome $\sim$ __time (non-compliance)

\begin{tabular}{l|c|c}
\hline Condition & Consistency & Coverage \\
\hline$\sim$ Capacity to comply (capa) & 0.68 & 0.63 \\
\hline$\sim$ Legal knowledge (lega) & 0.52 & 0.76 \\
\hline$\sim$ Deterrent effect of sanctions (dete) & $\mathbf{1 . 0 0}$ & 0.67 \\
\hline$\sim$ Cost-benefit analysis (cba) & $\mathbf{1 . 0 0}$ & 1.00 \\
\hline$\sim$ Descriptive social norms (socn) & $\mathbf{0 . 9 8}$ & 0.97 \\
\hline$\sim$ Morals (mora) & 0.58 & 1.00 \\
\hline$\sim$ Duty to obey (gdto) & 0.23 & 0.51 \\
\hline$\sim$ Procedural justice (proj) & $\mathbf{0 . 9 2}$ & 0.60 \\
\hline
\end{tabular}

The symbol ' $\sim$ ' indicates the absence of the condition.

Table 11 - Intermediate solution outcome ${ }^{\sim}$ __time (non-compliance)

\begin{tabular}{|c|c|c|c|c|c|c|}
\hline Solution 0_time & Path O_time.1 & & Path O_time.2 & & Path O_time.3 & \\
\hline Formula & $\begin{array}{l}\sim \text { mora* }{ }^{*} \text { socn } * \sim \text { cba* } \\
\sim \text { dete }{ }^{*} \text { capa } * \sim \text { lega }\end{array}$ & + & $\begin{array}{l}\sim \text { mora } * \sim \text { socn }{ }^{*} \sim \text { cba* } \\
\sim \text { dete }{ }^{*} \text { capa }{ }^{*} \sim \text { gdto }\end{array}$ & + & $\begin{array}{c}\text { socn }^{*} \sim \text { cba }^{*} \sim \text { dete }^{*} \quad-> \\
\sim \text { proj }\end{array}$ & $\begin{array}{l}\text { Non-compliance } \\
\text { (time interval) }\end{array}$ \\
\hline Raw coverage & 0.27 & & 0.12 & & 0.90 & \\
\hline Unique coverage & 0.03 & & 0.03 & & 0.61 & \\
\hline Consistency & 1.00 & & 1.00 & & 1.00 & \\
\hline Cases & $\begin{array}{c}43 ; 71 ; 73 ; 74 ; 77 ; \\
78 ; 80-84 ; 86 ; 90 ; \\
92 ; 94 ; 95\end{array}$ & & $\begin{array}{c}29 ; 36 ; 41 ; 48 ; 72 ; \\
73 ; 84\end{array}$ & & $\begin{array}{c}1 ; 3-7 ; 13 ; 14 ; 16-24 ; \\
29-31 ; 34 ; 39-43 ; 45 ; \\
48 ; 58 ; 59 ; 61 ; 64 ; \\
70 ; 71 ; 73-77 ; 79-82 ; \\
84 ; 86-95\end{array}$ & \\
\hline $\begin{array}{l}\text { Unexplained } \\
\text { cases }\end{array}$ & & & & & & $11 ; 12 ; 36$ \\
\hline Total cases & 16 farmers in total & & 7 farmers in total & & 54 farmers in total & $\begin{array}{l}3 \text { farmers in } \\
\text { total }\end{array}$ \\
\hline \multicolumn{7}{|c|}{$\begin{array}{r}\text { Solution coverage: } 0.97 \\
\text { Solution consistency: } 1.00\end{array}$} \\
\hline
\end{tabular}

The symbol ' ' indicates the absence of the condition. 


\section{Online appendix}

\section{Appendix A}

Table A1 Calibrating compliance conditions and outcomes for CSQCA

\begin{tabular}{ll}
\hline Items & $\begin{array}{l}\text { Brief introductions of interview } \\
\text { questions }\end{array}$ \\
\hline $\begin{array}{l}\text { Compliance outcomes } \\
\text { Use of types of } \\
\text { pesticides }\end{array}$ & $\begin{array}{l}\text { Which pesticides do you usually } \\
\text { use on what vegetables for what } \\
\text { pests or diseases? }\end{array}$ \\
Time interval & $\begin{array}{l}\text { What is your general time } \\
\text { interval between the last } \\
\text { pesticide applying and vegetable } \\
\text { pick-up? }\end{array}$
\end{tabular}

Scoring arrangement

0 earning last year?

\section{comply}

(Winter \& May

2001; Kagan \&

Scholz 1984)

\section{Legal}

knowledge (Winter \& May 2001; Kim 1999)

\section{Deterrence}

effect of sanctions

(Becker 1968; Thornton et al. 2005; Winter \& May 2001)
Do you know if the state has published any rules on (use of types of pesticides/disposal of pesticide containers/time interval)? If yes, please specify. How do you know this?

Assume that someone in the same business area as you does violate regulatory requirements related to [the type of pesticides that he is allowed to use/the time interval between applying pesticides and harvesting crops]. What is the possibility of this being found out? How high is the possibility? By whom? What negative and most serious effects would happen if punished?
In any way indicates that he/she has applied or will apply any type of illegal pesticides In any way indicate that he/she generally harvests vegetable at least a week later after pesticide spraying

In any way indicates family gross income < 40,000 RMB

Does not indicate in any way that he/she has applied or will apply any type of illegal pesticides In any way indicate that he/she generally harvests vegetable within a week after pesticide spraying

In any way indicates family income $\geq 40,000$ RMB

In any way indicates irrelevant legal knowledge on (use of types of pesticides/disposal of pesticide containers/time interval) from the law/other sources

In any way indicates low possibility of being discovered by the inspection bureau/other sources as well as no sanction impact
In any way indicates relevant legal knowledge on (use of types of pesticides/disposal of pesticide containers/time interval) from the law/other sources

In any way indicates high possibility of being discovered by the inspection bureau/other sources as well as an sanction impact 
Table A1 - Continued

\begin{tabular}{|c|c|c|c|}
\hline Items & $\begin{array}{l}\text { Brief introductions of interview } \\
\text { questions }\end{array}$ & $\begin{array}{l}\text { Scoring arrangement } \\
0\end{array}$ & 1 \\
\hline $\begin{array}{l}\text { Cost- benefit } \\
\text { analysis } \\
\text { (Kagan \& } \\
\text { Scholz 1984; } \\
\text { Winter \& May } \\
\text { 2001) }\end{array}$ & $\begin{array}{l}\text { How is your behavior (legal or } \\
\text { illegal) in comparison with the } \\
\text { alternatives (illegal or legal) in } \\
\text { terms of price and effectiveness } \\
\text { (for use of types of pesticides)/ } \\
\text { cost and earnings (for a time } \\
\text { interval)? }\end{array}$ & $\begin{array}{l}\text { In any way indicates } \\
\text { comparing with the } \\
\text { violation behavior, any } \\
\text { of the two specific } \\
\text { compliance behaviors is } \\
\text { less/more costly and } \\
\text { less effective/profitable }\end{array}$ & $\begin{array}{l}\text { In any way indicates } \\
\text { comparing with the } \\
\text { violation behavior, any } \\
\text { of the two specific } \\
\text { compliance behaviors is } \\
\text { less/more costly and } \\
\text { more } \\
\text { effective/profitable }\end{array}$ \\
\hline $\begin{array}{l}\text { Descriptive } \\
\text { social norms } \\
\text { (Cialdini 2007; } \\
\text { Tyran \& Feld } \\
\text { 2002) }\end{array}$ & $\begin{array}{l}\text { Do most other vegetable } \\
\text { farmers do the same as you do } \\
\text { on (any of the three specific } \\
\text { behaviors)? }\end{array}$ & $\begin{array}{l}\text { In any way indicates } \\
\text { that most other } \\
\text { vegetable farmers do } \\
\text { not comply with the } \\
\text { rules on (any of the } \\
\text { three specific pesticide } \\
\text { behaviors) }\end{array}$ & $\begin{array}{l}\text { In any way indicates } \\
\text { that most other } \\
\text { vegetable farmers } \\
\text { comply with the rules } \\
\text { on (any of the three } \\
\text { specific pesticide } \\
\text { behaviors) }\end{array}$ \\
\hline $\begin{array}{l}\text { Morals (Tyler } \\
\text { 1990) }\end{array}$ & $\begin{array}{l}\text { How do you think of people who } \\
\text { do [any of the two specific } \\
\text { violation behaviors]? }\end{array}$ & $\begin{array}{l}\text { In any way indicates in } \\
\text { such conditions the law } \\
\text { should not be obeyed }\end{array}$ & $\begin{array}{l}\text { In any way indicates in } \\
\text { such conditions the law } \\
\text { should be obeyed }\end{array}$ \\
\hline $\begin{array}{l}\text { General duty } \\
\text { to obey (Tyler } \\
\text { 1990; McGraw } \\
\text { \& Scholz 1991) }\end{array}$ & $\begin{array}{l}\text { Do you agree with the following } \\
\text { statement: people should obey } \\
\text { the law, even if it is a bad law, } \\
\text { even if it is not enforced, or } \\
\text { even when costs of obeying it } \\
\text { are high? }\end{array}$ & $\begin{array}{l}\text { In any way indicates } \\
\text { negative views on } \\
\text { general duty to obey }\end{array}$ & $\begin{array}{l}\text { In any way indicates } \\
\text { positive views on } \\
\text { general duty to obey }\end{array}$ \\
\hline $\begin{array}{l}\text { Procedural } \\
\text { justice (Tyler } \\
\text { 1990) }\end{array}$ & $\begin{array}{l}\text { Do you agree with the following } \\
\text { statements: officers of the local } \\
\text { agricultural bureau are honest; } \\
\text { decisions of local agricultural } \\
\text { bureau are always fair; overall, } \\
\text { how do you assess the work of } \\
\text { the local agricultural bureau? }\end{array}$ & $\begin{array}{l}\text { In any way indicates } \\
\text { negative views or mixed } \\
\text { views toward the three } \\
\text { aspects concerning } \\
\text { procedural justice }\end{array}$ & $\begin{array}{l}\text { In any way indicates } \\
\text { positive views toward all } \\
\text { the three aspects } \\
\text { concerning procedural } \\
\text { justice }\end{array}$ \\
\hline
\end{tabular}


Table A2 - Raw data matrix for compliance with type of regulation

\begin{tabular}{|c|c|c|c|c|c|c|c|c|c|}
\hline \multirow[t]{2}{*}{ Case } & \multicolumn{8}{|c|}{ Conditions } & \multirow[t]{2}{*}{ Outcome } \\
\hline & capa & lega & dete & $c b a$ & socn & mora & gdto & proj & \\
\hline 1 & 1 & 1 & 1 & 1 & 1 & 1 & 1 & 0 & 1 \\
\hline 2 & 1 & 1 & 0 & 0 & 0 & 0 & 0 & 0 & 0 \\
\hline 3 & 1 & 1 & 1 & 0 & 0 & 1 & 1 & 0 & 1 \\
\hline 4 & 1 & 1 & 1 & 1 & 1 & 1 & 1 & 0 & 1 \\
\hline 5 & 1 & 1 & 1 & 1 & 1 & 1 & 1 & 0 & 1 \\
\hline 6 & 0 & 1 & 1 & 1 & 1 & 1 & 1 & 0 & 1 \\
\hline 7 & 1 & 1 & 0 & 0 & 0 & 0 & 1 & 1 & 0 \\
\hline 8 & 1 & 1 & 1 & 1 & 1 & 1 & 1 & 0 & 1 \\
\hline 9 & 1 & 1 & 1 & 1 & 1 & 1 & 0 & 1 & 1 \\
\hline 10 & 1 & 1 & 1 & 1 & 1 & 1 & 0 & 0 & 1 \\
\hline 11 & 1 & 1 & 1 & 1 & 1 & 1 & 1 & 1 & 1 \\
\hline 12 & 0 & 1 & 1 & 1 & 1 & 1 & 1 & 0 & 1 \\
\hline 13 & 1 & 1 & 1 & 1 & 1 & 1 & 1 & 0 & 1 \\
\hline 14 & 1 & 1 & 1 & 1 & 1 & 1 & 1 & 0 & 1 \\
\hline 15 & 1 & 1 & 1 & 1 & 1 & 1 & 1 & 0 & 1 \\
\hline 16 & 1 & 1 & 1 & 1 & 1 & 1 & 1 & 0 & 1 \\
\hline 17 & 1 & 1 & 1 & 1 & 1 & 1 & 1 & 0 & 1 \\
\hline 18 & 1 & 1 & 1 & 1 & 1 & 1 & 1 & 0 & 1 \\
\hline 19 & 1 & 1 & 1 & 0 & 0 & 0 & 1 & 0 & 0 \\
\hline 20 & 1 & 1 & 1 & 1 & 1 & 1 & 1 & 0 & 1 \\
\hline 21 & 1 & 1 & 1 & 1 & 1 & 1 & 1 & 0 & 1 \\
\hline 22 & 1 & 1 & 1 & 1 & 1 & 1 & 1 & 0 & 1 \\
\hline 23 & 1 & 1 & 0 & 1 & 1 & 1 & 1 & 0 & 1 \\
\hline 24 & 1 & 1 & 1 & 1 & 1 & 1 & 0 & 0 & 1 \\
\hline 25 & 1 & 1 & 0 & 1 & 0 & 1 & 0 & 0 & 1 \\
\hline 26 & 0 & 1 & 1 & 1 & 1 & 1 & 0 & 0 & 1 \\
\hline 27 & 0 & 0 & 1 & 1 & 1 & 1 & 1 & 0 & 1 \\
\hline 28 & 0 & 1 & 0 & 0 & 1 & 1 & 1 & 0 & 1 \\
\hline 29 & 0 & 1 & 0 & 0 & 0 & 0 & 0 & 0 & 0 \\
\hline 30 & 0 & 1 & 0 & 1 & 1 & 1 & 1 & 0 & 1 \\
\hline 31 & 0 & 1 & 0 & 0 & 0 & 0 & 1 & 0 & 0 \\
\hline 32 & 1 & 1 & 0 & 1 & 1 & 1 & 1 & 0 & 1 \\
\hline 33 & 0 & 1 & 0 & 0 & 0 & 0 & 0 & 1 & 0 \\
\hline 34 & 0 & 0 & 0 & 0 & 0 & 0 & 1 & 0 & 0 \\
\hline 35 & 0 & 1 & 1 & 1 & 1 & 1 & 1 & 0 & 1 \\
\hline 36 & 0 & 1 & 0 & 0 & 0 & 1 & 0 & 1 & 0 \\
\hline 37 & 0 & 1 & 1 & 1 & 1 & 1 & 1 & 0 & 1 \\
\hline 38 & 1 & 1 & 0 & 0 & 0 & 0 & 0 & 0 & 0 \\
\hline 39 & 0 & 1 & 0 & 0 & 0 & 0 & 1 & 0 & 0 \\
\hline 40 & 0 & 1 & 0 & 0 & 0 & 0 & 0 & 0 & 0 \\
\hline 41 & 0 & 1 & 1 & 1 & 1 & 1 & 0 & 0 & 1 \\
\hline 42 & 0 & 1 & 1 & 1 & 1 & 1 & 0 & 0 & 1 \\
\hline 43 & 0 & 1 & 0 & 0 & 0 & 0 & 1 & 0 & 0 \\
\hline 44 & 0 & 0 & 0 & 1 & 1 & 1 & 1 & 0 & 1 \\
\hline
\end{tabular}


Table A2 - Continued

\begin{tabular}{|c|c|c|c|c|c|c|c|c|c|}
\hline \multirow[t]{2}{*}{ Case } & \multicolumn{8}{|c|}{ Conditions } & \multirow[t]{2}{*}{ Outcome } \\
\hline & capa & lega & dete & $c b a$ & socn & mora & gdto & proj & \\
\hline 45 & 0 & 1 & 0 & 1 & 1 & 1 & 1 & 0 & 1 \\
\hline 46 & 0 & 1 & 1 & 1 & 1 & 1 & 0 & 0 & 1 \\
\hline 47 & 1 & 1 & 0 & 0 & 0 & 0 & 1 & 0 & 0 \\
\hline 48 & 0 & 0 & 1 & 1 & 1 & 1 & 0 & 0 & 1 \\
\hline 49 & 1 & 1 & 1 & 1 & 1 & 1 & 1 & 0 & 1 \\
\hline 50 & 0 & 1 & 1 & 1 & 1 & 1 & 1 & 0 & 1 \\
\hline 51 & 0 & 0 & 0 & 1 & 1 & 1 & 1 & 0 & 1 \\
\hline 52 & 0 & 0 & 0 & 1 & 1 & 1 & 1 & 0 & 1 \\
\hline 53 & 0 & 1 & 1 & 1 & 1 & 1 & 0 & 0 & 1 \\
\hline 54 & 0 & 0 & 1 & 0 & 1 & 1 & 1 & 0 & 1 \\
\hline 55 & 0 & 0 & 0 & 0 & 1 & 1 & 0 & 0 & 1 \\
\hline 56 & 0 & 0 & 0 & 1 & 1 & 1 & 1 & 0 & 1 \\
\hline 57 & 0 & 1 & 1 & 1 & 1 & 1 & 1 & 0 & 1 \\
\hline 58 & 0 & 0 & 1 & 0 & 1 & 1 & 0 & 0 & 1 \\
\hline 59 & 0 & 1 & 1 & 1 & 1 & 1 & 1 & 0 & 1 \\
\hline 60 & 0 & 1 & 1 & 1 & 1 & 1 & 0 & 0 & 1 \\
\hline 61 & 1 & 1 & 1 & 1 & 1 & 1 & 1 & 0 & 1 \\
\hline 62 & 0 & 1 & 0 & 1 & 1 & 1 & 1 & 0 & 1 \\
\hline 63 & 0 & 1 & 1 & 1 & 1 & 1 & 0 & 0 & 1 \\
\hline 64 & 1 & 1 & 1 & 1 & 1 & 1 & 1 & 0 & 1 \\
\hline 65 & 0 & 1 & 1 & 1 & 1 & 1 & 1 & 0 & 1 \\
\hline 66 & 0 & 1 & 1 & 1 & 1 & 1 & 1 & 0 & 1 \\
\hline 67 & 0 & 1 & 0 & 1 & 1 & 1 & 1 & 0 & 1 \\
\hline 68 & 1 & 1 & 0 & 1 & 1 & 1 & 1 & 0 & 1 \\
\hline 69 & 0 & 1 & 0 & 1 & 1 & 1 & 1 & 0 & 1 \\
\hline 70 & 0 & 1 & 1 & 1 & 1 & 1 & 1 & 0 & 1 \\
\hline 71 & 0 & 1 & 1 & 1 & 1 & 1 & 1 & 0 & 1 \\
\hline 72 & 0 & 1 & 1 & 1 & 1 & 1 & 0 & 1 & 1 \\
\hline 73 & 0 & 1 & 1 & 1 & 1 & 1 & 0 & 0 & 1 \\
\hline 74 & 0 & 1 & 1 & 1 & 1 & 1 & 1 & 0 & 1 \\
\hline 75 & 0 & 1 & 1 & 1 & 1 & 1 & 1 & 0 & 1 \\
\hline 76 & 0 & 1 & 1 & 1 & 1 & 1 & 0 & 0 & 1 \\
\hline 77 & 0 & 1 & 1 & 1 & 1 & 1 & 1 & 0 & 1 \\
\hline 78 & 0 & 1 & 1 & 1 & 1 & 1 & 1 & 1 & 1 \\
\hline 79 & 0 & 1 & 1 & 1 & 1 & 1 & 1 & 0 & 1 \\
\hline 80 & 0 & 1 & 1 & 1 & 1 & 1 & 1 & 0 & 1 \\
\hline 81 & 0 & 1 & 1 & 1 & 1 & 1 & 1 & 0 & 1 \\
\hline 82 & 0 & 1 & 1 & 1 & 1 & 1 & 1 & 0 & 1 \\
\hline 83 & 0 & 1 & 1 & 1 & 1 & 1 & 1 & 1 & 1 \\
\hline 84 & 0 & 1 & 1 & 1 & 1 & 1 & 0 & 0 & 1 \\
\hline 85 & 0 & 1 & 1 & 1 & 1 & 1 & 1 & 1 & 1 \\
\hline 86 & 0 & 1 & 1 & 1 & 1 & 1 & 1 & 0 & 1 \\
\hline 87 & 0 & 1 & 1 & 1 & 1 & 1 & 0 & 0 & 1 \\
\hline 88 & 0 & 1 & 1 & 0 & 1 & 1 & 1 & 0 & 1 \\
\hline
\end{tabular}


Table A2-Continued

\begin{tabular}{|c|c|c|c|c|c|c|c|c|c|}
\hline \multirow[t]{2}{*}{ Case } & \multicolumn{8}{|c|}{ Conditions } & \multirow[t]{2}{*}{ Outcome } \\
\hline & capa & lega & dete & $c b a$ & socn & mora & gdto & proj & \\
\hline 89 & 0 & 1 & 1 & 1 & 1 & 1 & 0 & 0 & 1 \\
\hline 90 & 0 & 1 & 1 & 1 & 1 & 1 & 1 & 0 & 1 \\
\hline 91 & 0 & 1 & 1 & 1 & 1 & 1 & 1 & 0 & 1 \\
\hline 92 & 0 & 1 & 1 & 1 & 1 & 1 & 1 & 0 & 1 \\
\hline 93 & 0 & 1 & 1 & 1 & 1 & 1 & 1 & 0 & 1 \\
\hline 94 & 0 & 1 & 1 & 1 & 1 & 1 & 1 & 0 & 1 \\
\hline 95 & 0 & 1 & 1 & 1 & 1 & 1 & 1 & 0 & 1 \\
\hline 96 & 1 & 1 & 1 & 1 & 1 & 1 & 1 & 0 & 1 \\
\hline 97 & 1 & 1 & 1 & 1 & 1 & 1 & 1 & 0 & 1 \\
\hline 98 & 1 & 1 & 1 & 1 & 1 & 1 & 1 & 0 & 1 \\
\hline 99 & 1 & 1 & 1 & 1 & 1 & 1 & 0 & 1 & 1 \\
\hline 100 & 1 & 1 & 1 & 1 & 1 & 1 & 1 & 0 & 1 \\
\hline 101 & 1 & 1 & 1 & 1 & 1 & 1 & 1 & 0 & 1 \\
\hline
\end{tabular}

Abbreviations: capa=capacity to comply; lega=legal knowledge; dete=deterrent effect of sanctions; cba=costbenefit analysis; socn=descriptive social norms; mora=morals; gdto=duty to obey; proj=procedural justice; Freq. $=$ frequency 
Table A3 - Raw data matrix for compliance with time interval

\begin{tabular}{|c|c|c|c|c|c|c|c|c|c|}
\hline \multirow[t]{2}{*}{ Case } & \multicolumn{8}{|c|}{ Conditions } & \multirow[t]{2}{*}{ Outcome } \\
\hline & capa & lega & dete & $c b a$ & socn & mora & gdto & proj & \\
\hline 1 & 1 & 1 & 0 & 0 & 0 & 1 & 1 & 0 & 0 \\
\hline 2 & 1 & 1 & 0 & 1 & 0 & 1 & 0 & 0 & 1 \\
\hline 3 & 1 & 1 & 0 & 0 & 0 & 1 & 1 & 0 & 0 \\
\hline 4 & 1 & 1 & 0 & 0 & 0 & 1 & 1 & 0 & 0 \\
\hline 5 & 1 & 0 & 0 & 0 & 0 & 0 & 1 & 0 & 0 \\
\hline 6 & 0 & 1 & 0 & 0 & 0 & 1 & 1 & 0 & 0 \\
\hline 7 & 1 & 1 & 0 & 1 & 1 & 1 & 1 & 1 & 1 \\
\hline 8 & 1 & 1 & 0 & 0 & 0 & 0 & 1 & 0 & 0 \\
\hline 9 & 1 & 1 & 0 & 1 & 1 & 1 & 0 & 1 & 1 \\
\hline 10 & 1 & 1 & 0 & 1 & 1 & 1 & 0 & 0 & 1 \\
\hline 11 & 1 & 1 & 0 & 0 & 0 & 0 & 1 & 1 & 0 \\
\hline 12 & 0 & 1 & 0 & 0 & 1 & 1 & 1 & 0 & 0 \\
\hline 13 & 1 & 1 & 0 & 0 & 0 & 0 & 1 & 0 & 0 \\
\hline 14 & 1 & 0 & 0 & 0 & 0 & 0 & 1 & 0 & 0 \\
\hline 15 & 1 & 0 & 0 & 1 & 1 & 1 & 1 & 0 & 1 \\
\hline 16 & 1 & 1 & 0 & 0 & 0 & 0 & 1 & 0 & 0 \\
\hline 17 & 1 & 1 & 0 & 0 & 0 & 0 & 1 & 0 & 0 \\
\hline 18 & 1 & 1 & 0 & 0 & 0 & 0 & 1 & 0 & 0 \\
\hline 19 & 1 & 1 & 0 & 0 & 0 & 0 & 1 & 0 & 0 \\
\hline 20 & 1 & 0 & 0 & 0 & 0 & 1 & 1 & 0 & 0 \\
\hline 21 & 1 & 0 & 0 & 0 & 0 & 0 & 1 & 0 & 0 \\
\hline 22 & 1 & 1 & 0 & 0 & 0 & 1 & 1 & 0 & 0 \\
\hline 23 & 1 & 0 & 0 & 0 & 0 & 0 & 1 & 0 & 0 \\
\hline 24 & 1 & 1 & 0 & 0 & 0 & 1 & 0 & 0 & 0 \\
\hline 25 & 1 & 1 & 0 & 1 & 1 & 1 & 0 & 0 & 1 \\
\hline 26 & 0 & 1 & 0 & 1 & 1 & 1 & 0 & 0 & 1 \\
\hline 27 & 0 & 0 & 1 & 1 & 1 & 1 & 1 & 0 & 1 \\
\hline 28 & 0 & 0 & 0 & 1 & 1 & 1 & 1 & 0 & 1 \\
\hline 29 & 0 & 1 & 0 & 0 & 0 & 0 & 0 & 0 & 0 \\
\hline 30 & 0 & 1 & 0 & 0 & 0 & 1 & 1 & 0 & 0 \\
\hline 31 & 0 & 1 & 0 & 0 & 0 & 1 & 1 & 0 & 0 \\
\hline 32 & 1 & 0 & 1 & 1 & 1 & 1 & 1 & 0 & 1 \\
\hline 33 & 0 & 1 & 0 & 1 & 1 & 1 & 0 & 1 & 1 \\
\hline 34 & 0 & 0 & 0 & 0 & 0 & 1 & 1 & 0 & 0 \\
\hline 35 & 0 & 1 & 0 & 1 & 1 & 1 & 1 & 0 & 1 \\
\hline 36 & 0 & 1 & 0 & 0 & 0 & 0 & 0 & 1 & 0 \\
\hline 37 & 0 & 1 & 1 & 1 & 1 & 1 & 1 & 0 & 1 \\
\hline 38 & 1 & 1 & 0 & 1 & 0 & 1 & 0 & 0 & 1 \\
\hline 39 & 0 & 1 & 0 & 0 & 0 & 1 & 1 & 0 & 0 \\
\hline 40 & 0 & 0 & 0 & 0 & 0 & 1 & 0 & 0 & 0 \\
\hline 41 & 0 & 1 & 0 & 0 & 0 & 0 & 0 & 0 & 0 \\
\hline 42 & 0 & 1 & 0 & 0 & 0 & 1 & 0 & 0 & 0 \\
\hline 43 & 0 & 0 & 0 & 0 & 0 & 0 & 1 & 0 & 0 \\
\hline 44 & 0 & 1 & 0 & 1 & 1 & 1 & 1 & 0 & 1 \\
\hline
\end{tabular}


Table A3-Continued

\begin{tabular}{|c|c|c|c|c|c|c|c|c|c|}
\hline \multirow[t]{2}{*}{ Case } & \multicolumn{8}{|c|}{ Conditions } & \multirow[t]{2}{*}{ Outcome } \\
\hline & capa & lega & dete & $c b a$ & socn & mora & gdto & proj & \\
\hline 45 & 0 & 1 & 0 & 0 & 0 & 0 & 1 & 0 & 0 \\
\hline 46 & 0 & 1 & 1 & 1 & 1 & 1 & 0 & 0 & 1 \\
\hline 47 & 1 & 1 & 0 & 1 & 1 & 1 & 1 & 0 & 1 \\
\hline 48 & 0 & 1 & 0 & 0 & 0 & 0 & 0 & 0 & 0 \\
\hline 49 & 1 & 1 & 0 & 1 & 1 & 1 & 1 & 0 & 1 \\
\hline 50 & 0 & 1 & 0 & 1 & 1 & 1 & 1 & 0 & 1 \\
\hline 51 & 0 & 1 & 0 & 1 & 1 & 1 & 1 & 0 & 1 \\
\hline 52 & 0 & 0 & 0 & 1 & 1 & 1 & 1 & 0 & 1 \\
\hline 53 & 0 & 1 & 0 & 1 & 1 & 1 & 0 & 0 & 1 \\
\hline 54 & 0 & 0 & 0 & 1 & 1 & 1 & 1 & 0 & 1 \\
\hline 55 & 0 & 1 & 0 & 1 & 1 & 1 & 0 & 0 & 1 \\
\hline 56 & 0 & 1 & 0 & 1 & 1 & 1 & 1 & 0 & 1 \\
\hline 57 & 0 & 0 & 0 & 1 & 1 & 1 & 1 & 0 & 1 \\
\hline 58 & 0 & 0 & 0 & 0 & 0 & 1 & 0 & 0 & 0 \\
\hline 59 & 0 & 1 & 0 & 0 & 0 & 1 & 1 & 0 & 0 \\
\hline 60 & 0 & 1 & 0 & 1 & 1 & 1 & 0 & 0 & 1 \\
\hline 61 & 1 & 0 & 0 & 0 & 0 & 1 & 1 & 0 & 0 \\
\hline 62 & 0 & 1 & 0 & 1 & 1 & 1 & 1 & 0 & 1 \\
\hline 63 & 0 & 1 & 0 & 1 & 1 & 1 & 0 & 0 & 1 \\
\hline 64 & 1 & 0 & 0 & 0 & 0 & 0 & 1 & 0 & 0 \\
\hline 65 & 0 & 0 & 0 & 1 & 1 & 1 & 1 & 0 & 1 \\
\hline 66 & 0 & 1 & 0 & 1 & 1 & 1 & 1 & 0 & 1 \\
\hline 67 & 0 & 1 & 0 & 1 & 1 & 1 & 1 & 0 & 1 \\
\hline 68 & 1 & 1 & 0 & 1 & 1 & 1 & 1 & 0 & 1 \\
\hline 69 & 0 & 0 & 0 & 1 & 1 & 1 & 1 & 0 & 1 \\
\hline 70 & 0 & 0 & 0 & 0 & 0 & 1 & 1 & 0 & 0 \\
\hline 71 & 0 & 0 & 0 & 0 & 0 & 0 & 1 & 0 & 0 \\
\hline 72 & 0 & 1 & 0 & 0 & 0 & 0 & 0 & 1 & 0 \\
\hline 73 & 0 & 0 & 0 & 0 & 0 & 0 & 0 & 0 & 0 \\
\hline 74 & 0 & 0 & 0 & 0 & 0 & 0 & 1 & 0 & 0 \\
\hline 75 & 0 & 0 & 0 & 0 & 0 & 1 & 1 & 0 & 0 \\
\hline 76 & 0 & 0 & 0 & 0 & 0 & 1 & 0 & 0 & 0 \\
\hline 77 & 0 & 0 & 0 & 0 & 0 & 0 & 1 & 0 & 0 \\
\hline 78 & 0 & 0 & 0 & 0 & 0 & 0 & 1 & 1 & 0 \\
\hline 79 & 0 & 0 & 0 & 0 & 0 & 1 & 1 & 0 & 0 \\
\hline 80 & 0 & 0 & 0 & 0 & 0 & 0 & 1 & 0 & 0 \\
\hline 81 & 0 & 0 & 0 & 0 & 0 & 0 & 1 & 0 & 0 \\
\hline 82 & 0 & 0 & 0 & 0 & 0 & 0 & 1 & 0 & 0 \\
\hline 83 & 0 & 0 & 0 & 0 & 0 & 0 & 1 & 1 & 0 \\
\hline 84 & 0 & 0 & 0 & 0 & 0 & 0 & 0 & 0 & 0 \\
\hline 85 & 0 & 0 & 1 & 1 & 1 & 1 & 1 & 1 & 1 \\
\hline 86 & 0 & 0 & 0 & 0 & 0 & 0 & 1 & 0 & 0 \\
\hline 87 & 0 & 1 & 0 & 0 & 0 & 1 & 0 & 0 & 0 \\
\hline 88 & 0 & 1 & 0 & 0 & 0 & 0 & 1 & 0 & 0 \\
\hline
\end{tabular}


Table A3-Continued

\begin{tabular}{|c|c|c|c|c|c|c|c|c|c|}
\hline \multirow[t]{2}{*}{ Case } & \multicolumn{8}{|c|}{ Conditions } & \multirow[t]{2}{*}{ Outcome } \\
\hline & capa & lega & dete & $c b a$ & socn & mora & gdto & proj & \\
\hline 89 & 0 & 1 & 0 & 0 & 0 & 1 & 0 & 0 & 0 \\
\hline 90 & 0 & 0 & 0 & 0 & 0 & 0 & 1 & 0 & 0 \\
\hline 91 & 0 & 0 & 0 & 0 & 0 & 1 & 1 & 0 & 0 \\
\hline 92 & 0 & 0 & 0 & 0 & 0 & 0 & 1 & 0 & 0 \\
\hline 93 & 0 & 1 & 0 & 0 & 0 & 1 & 1 & 0 & 0 \\
\hline 94 & 0 & 0 & 0 & 0 & 0 & 0 & 1 & 0 & 0 \\
\hline 95 & 0 & 0 & 0 & 0 & 0 & 0 & 1 & 0 & 0 \\
\hline 96 & 1 & 1 & 1 & 1 & 1 & 1 & 1 & 0 & 1 \\
\hline 97 & 1 & 1 & 1 & 1 & 1 & 1 & 1 & 0 & 1 \\
\hline 98 & 1 & 1 & 1 & 1 & 1 & 1 & 1 & 0 & 1 \\
\hline 99 & 1 & 1 & 1 & 1 & 1 & 1 & 0 & 1 & 1 \\
\hline 100 & 1 & 1 & 1 & 1 & 1 & 1 & 1 & 0 & 1 \\
\hline 101 & 1 & 1 & 1 & 1 & 1 & 1 & 1 & 0 & 1 \\
\hline
\end{tabular}

Abbreviations: as per table $\mathrm{A} 2$. 


\section{Appendix B}

Table B1 - Truth table for outcome O_time

\begin{tabular}{|c|c|c|c|c|c|c|c|c|c|c|}
\hline \multirow[t]{2}{*}{ Row } & \multicolumn{8}{|c|}{ Conditions } & \multirow[t]{2}{*}{ Freq. } & \multirow{2}{*}{$\begin{array}{c}\mathrm{O}_{-} \\
\text {time }\end{array}$} \\
\hline & capa & lega & dete & $c b a$ & socn & mora & gdto & proj & & \\
\hline 1 & 0 & 1 & 0 & 1 & 1 & 1 & 1 & 0 & 8 & 1 \\
\hline 2 & 0 & 0 & 0 & 1 & 1 & 1 & 1 & 0 & 6 & 1 \\
\hline 3 & 0 & 1 & 0 & 1 & 1 & 1 & 0 & 0 & 5 & 1 \\
\hline 4 & 1 & 1 & 1 & 1 & 1 & 1 & 1 & 0 & 5 & 1 \\
\hline 5 & 1 & 1 & 0 & 1 & 1 & 1 & 1 & 0 & 3 & 1 \\
\hline 6 & 1 & 1 & 0 & 1 & 0 & 1 & 0 & 0 & 2 & 1 \\
\hline 7 & 1 & 1 & 0 & 1 & 1 & 1 & 0 & 0 & 2 & 1 \\
\hline 8 & 0 & 0 & 1 & 1 & 1 & 1 & 1 & 0 & 1 & 1 \\
\hline 9 & 0 & 0 & 1 & 1 & 1 & 1 & 1 & 1 & 1 & 1 \\
\hline 10 & 0 & 1 & 0 & 1 & 1 & 1 & 0 & 1 & 1 & 1 \\
\hline 11 & 0 & 1 & 1 & 1 & 1 & 1 & 0 & 0 & 1 & 1 \\
\hline 12 & 0 & 1 & 1 & 1 & 1 & 1 & 1 & 0 & 1 & 1 \\
\hline 13 & 1 & 0 & 0 & 1 & 1 & 1 & 1 & 0 & 1 & 1 \\
\hline 14 & 1 & 0 & 1 & 1 & 1 & 1 & 1 & 0 & 1 & 1 \\
\hline 15 & 1 & 1 & 0 & 1 & 1 & 1 & 0 & 1 & 1 & 1 \\
\hline 16 & 1 & 1 & 0 & 1 & 1 & 1 & 1 & 1 & 1 & 1 \\
\hline 17 & 1 & 1 & 1 & 1 & 1 & 1 & 0 & 1 & 1 & 1 \\
\hline 18 & 0 & 0 & 0 & 0 & 0 & 0 & 1 & 0 & 12 & 0 \\
\hline 19 & 0 & 1 & 0 & 0 & 0 & 1 & 1 & 0 & 6 & 0 \\
\hline 20 & 1 & 1 & 0 & 0 & 0 & 0 & 1 & 0 & 6 & 0 \\
\hline 21 & 0 & 0 & 0 & 0 & 0 & 1 & 1 & 0 & 5 & 0 \\
\hline 22 & 1 & 0 & 0 & 0 & 0 & 0 & 1 & 0 & 5 & 0 \\
\hline 23 & 1 & 1 & 0 & 0 & 0 & 1 & 1 & 0 & 4 & 0 \\
\hline 24 & 0 & 0 & 0 & 0 & 0 & 1 & 0 & 0 & 3 & 0 \\
\hline 25 & 0 & 1 & 0 & 0 & 0 & 0 & 0 & 0 & 3 & 0 \\
\hline 26 & 0 & 1 & 0 & 0 & 0 & 1 & 0 & 0 & 3 & 0 \\
\hline 27 & 0 & 0 & 0 & 0 & 0 & 0 & 0 & 0 & 2 & 0 \\
\hline 28 & 0 & 0 & 0 & 0 & 0 & 0 & 1 & 1 & 2 & 0 \\
\hline 29 & 0 & 1 & 0 & 0 & 0 & 0 & 0 & 1 & 2 & 0 \\
\hline 30 & 0 & 1 & 0 & 0 & 0 & 0 & 1 & 0 & 2 & 0 \\
\hline 31 & 1 & 0 & 0 & 0 & 0 & 1 & 1 & 0 & 2 & 0 \\
\hline 32 & 0 & 1 & 0 & 0 & 1 & 1 & 1 & 0 & 1 & 0 \\
\hline 33 & 1 & 1 & 0 & 0 & 0 & 0 & 1 & 1 & 1 & 0 \\
\hline 34 & 1 & 1 & 0 & 0 & 0 & 1 & 0 & 0 & 1 & 0 \\
\hline \multicolumn{9}{|c|}{ Rows 35 - 256: logical remainders } & 222 & ? \\
\hline
\end{tabular}

Abbreviations: as per table $\mathrm{A} 2$. 
Table B2 - Truth table for outcome O_time

\begin{tabular}{|c|c|c|c|c|c|c|c|c|c|c|}
\hline \multirow[t]{2}{*}{ Row } & \multicolumn{8}{|c|}{ Conditions } & \multirow[t]{2}{*}{ Freq. } & \multirow{2}{*}{$\begin{array}{c}\mathrm{O}_{-} \\
\text {time }\end{array}$} \\
\hline & capa & lega & dete & $c b a$ & socn & mora & gdto & proj & & \\
\hline 1 & 0 & 1 & 0 & 0 & 0 & 0 & 1 & 0 & 3 & 1 \\
\hline 2 & 0 & 1 & 0 & 0 & 0 & 0 & 0 & 0 & 2 & 1 \\
\hline 3 & 1 & 1 & 0 & 0 & 0 & 0 & 0 & 0 & 2 & 1 \\
\hline 4 & 0 & 0 & 0 & 0 & 0 & 0 & 1 & 0 & 1 & 1 \\
\hline 5 & 0 & 1 & 0 & 0 & 0 & 0 & 0 & 1 & 1 & 1 \\
\hline 6 & 0 & 1 & 0 & 0 & 0 & 1 & 0 & 1 & 1 & 1 \\
\hline 7 & 1 & 1 & 0 & 0 & 0 & 0 & 1 & 0 & 1 & 1 \\
\hline 8 & 1 & 1 & 0 & 0 & 0 & 0 & 1 & 1 & 1 & 1 \\
\hline 9 & 1 & 1 & 1 & 0 & 0 & 0 & 1 & 0 & 1 & 1 \\
\hline 10 & 0 & 1 & 1 & 1 & 1 & 1 & 1 & 0 & 25 & 0 \\
\hline 11 & 1 & 1 & 1 & 1 & 1 & 1 & 1 & 0 & 21 & 0 \\
\hline 12 & 0 & 1 & 1 & 1 & 1 & 1 & 0 & 0 & 12 & 0 \\
\hline 13 & 0 & 1 & 0 & 1 & 1 & 1 & 1 & 0 & 5 & 0 \\
\hline 14 & 0 & 0 & 0 & 1 & 1 & 1 & 1 & 0 & 4 & 0 \\
\hline 15 & 0 & 1 & 1 & 1 & 1 & 1 & 1 & 1 & 3 & 0 \\
\hline 16 & 1 & 1 & 0 & 1 & 1 & 1 & 1 & 0 & 3 & 0 \\
\hline 17 & 1 & 1 & 1 & 1 & 1 & 1 & 0 & 0 & 2 & 0 \\
\hline 18 & 1 & 1 & 1 & 1 & 1 & 1 & 0 & 1 & 2 & 0 \\
\hline 19 & 0 & 0 & 0 & 0 & 1 & 1 & 0 & 0 & 1 & 0 \\
\hline 20 & 0 & 0 & 1 & 0 & 1 & 1 & 0 & 0 & 1 & 0 \\
\hline 21 & 0 & 0 & 1 & 0 & 1 & 1 & 1 & 0 & 1 & 0 \\
\hline 22 & 0 & 0 & 1 & 1 & 1 & 1 & 0 & 0 & 1 & 0 \\
\hline 23 & 0 & 0 & 1 & 1 & 1 & 1 & 1 & 0 & 1 & 0 \\
\hline 24 & 0 & 1 & 0 & 0 & 1 & 1 & 1 & 0 & 1 & 0 \\
\hline 25 & 0 & 1 & 1 & 0 & 1 & 1 & 1 & 0 & 1 & 0 \\
\hline 26 & 0 & 1 & 1 & 1 & 1 & 1 & 0 & 1 & 1 & 0 \\
\hline 27 & 1 & 1 & 0 & 1 & 0 & 1 & 0 & 0 & 1 & 0 \\
\hline 28 & 1 & 1 & 1 & 0 & 0 & 1 & 1 & 0 & 1 & 0 \\
\hline 29 & 1 & 1 & 1 & 1 & 1 & 1 & 1 & 1 & 1 & 0 \\
\hline \multicolumn{9}{|c|}{ Rows 30 - 256: logical remainders } & 227 & $?$ \\
\hline
\end{tabular}

Abbreviations: as per table A2. 
Table B3 - Truth table for outcome O_time

\begin{tabular}{|c|c|c|c|c|c|c|c|c|c|c|}
\hline \multirow[t]{2}{*}{ Row } & \multicolumn{8}{|c|}{ Conditions } & \multirow[t]{2}{*}{ Freq. } & \multirow{2}{*}{$\underset{\text { time }}{O_{-}}$} \\
\hline & capa & lega & dete & $c b a$ & socn & mora & gdto & proj & & \\
\hline 1 & 0 & 0 & 0 & 0 & 0 & 0 & 1 & 0 & 12 & 1 \\
\hline 2 & 0 & 1 & 0 & 0 & 0 & 1 & 1 & 0 & 6 & 1 \\
\hline 3 & 1 & 1 & 0 & 0 & 0 & 0 & 1 & 0 & 6 & 1 \\
\hline 4 & 0 & 0 & 0 & 0 & 0 & 1 & 1 & 0 & 5 & 1 \\
\hline 5 & 1 & 0 & 0 & 0 & 0 & 0 & 1 & 0 & 5 & 1 \\
\hline 6 & 1 & 1 & 0 & 0 & 0 & 1 & 1 & 0 & 4 & 1 \\
\hline 7 & 0 & 0 & 0 & 0 & 0 & 1 & 0 & 0 & 3 & 1 \\
\hline 8 & 0 & 1 & 0 & 0 & 0 & 0 & 0 & 0 & 3 & 1 \\
\hline 9 & 0 & 1 & 0 & 0 & 0 & 1 & 0 & 0 & 3 & 1 \\
\hline 10 & 0 & 0 & 0 & 0 & 0 & 0 & 0 & 0 & 2 & 1 \\
\hline 11 & 0 & 0 & 0 & 0 & 0 & 0 & 1 & 1 & 2 & 1 \\
\hline 12 & 0 & 1 & 0 & 0 & 0 & 0 & 0 & 1 & 2 & 1 \\
\hline 13 & 0 & 1 & 0 & 0 & 0 & 0 & 1 & 0 & 2 & 1 \\
\hline 14 & 1 & 0 & 0 & 0 & 0 & 1 & 1 & 0 & 2 & 1 \\
\hline 15 & 0 & 1 & 0 & 0 & 1 & 1 & 1 & 0 & 1 & 1 \\
\hline 16 & 1 & 1 & 0 & 0 & 0 & 0 & 1 & 1 & 1 & 1 \\
\hline 17 & 1 & 1 & 0 & 0 & 0 & 1 & 0 & 0 & 1 & 1 \\
\hline 18 & 0 & 1 & 0 & 1 & 1 & 1 & 1 & 0 & 8 & 0 \\
\hline 19 & 0 & 0 & 0 & 1 & 1 & 1 & 1 & 0 & 6 & 0 \\
\hline 20 & 0 & 1 & 0 & 1 & 1 & 1 & 0 & 0 & 5 & 0 \\
\hline 21 & 1 & 1 & 1 & 1 & 1 & 1 & 1 & 0 & 5 & 0 \\
\hline 22 & 1 & 1 & 0 & 1 & 1 & 1 & 1 & 0 & 3 & 0 \\
\hline 23 & 1 & 1 & 0 & 1 & 0 & 1 & 0 & 0 & 2 & 0 \\
\hline 24 & 1 & 1 & 0 & 1 & 1 & 1 & 0 & 0 & 2 & 0 \\
\hline 25 & 0 & 0 & 1 & 1 & 1 & 1 & 1 & 0 & 1 & 0 \\
\hline 26 & 0 & 0 & 1 & 1 & 1 & 1 & 1 & 1 & 1 & 0 \\
\hline 27 & 0 & 1 & 0 & 1 & 1 & 1 & 0 & 1 & 1 & 0 \\
\hline 28 & 0 & 1 & 1 & 1 & 1 & 1 & 0 & 0 & 1 & 0 \\
\hline 29 & 0 & 1 & 1 & 1 & 1 & 1 & 1 & 0 & 1 & 0 \\
\hline 30 & 1 & 0 & 0 & 1 & 1 & 1 & 1 & 0 & 1 & 0 \\
\hline 31 & 1 & 0 & 1 & 1 & 1 & 1 & 1 & 0 & 1 & 0 \\
\hline 32 & 1 & 1 & 0 & 1 & 1 & 1 & 0 & 1 & 1 & 0 \\
\hline 33 & 1 & 1 & 0 & 1 & 1 & 1 & 1 & 1 & 1 & 0 \\
\hline 34 & 1 & 1 & 1 & 1 & 1 & 1 & 0 & 1 & 1 & 0 \\
\hline
\end{tabular}

Abbreviations: as per table A2. 


\section{References}

Ayres, I., \& Braithwaite, J. (1992). Responsive Regulation. New York: Oxford University Press.

Becker, G. S., \& Stigler, G. J. (1974). Law Enforcement, Malfeasance, and Compensation of Enforcers. Journal of Legal Studies, 3(1), 1-18.

Berg-Schlosser, D. (2/12). Mixed Methods in Comparative Politics. New York: Palgrave.

Black, J. M. (1996). An Economic Analysis of Regulation. Oxford Journal of Legal Studies, 16(4), 699711.

Braithwaite, V. (2009). Defiance in taxation and governance. Cheltenham: Eldward Elgar.

Cialdini, R. (2003). Crafting Normative Messages to Protect the Environment. Current directions in psychological science, 12(4), 105-109.

Cooper, B., \& Glaesser, J. (2011). Using case-based approaches to analyse large datasets. International Journal of Social Research Methodology, 14(1), 31-48.

Deutsch, M., \& Gerald, H. (1955). A study of normative and informational social influences upon individual judgment. Journal of Abnormal and Social Psychology, 51(3), 629-636.

Duhigg, C. (2012). The Power of Habit. New York: Random House.

Ehrlich, P. (1972). Deterrent Effect of Criminal Law Enforcement. Journal of Legal Studies, 1(2), 259276.

Elffers, H., Wiegel, R., \& Hessing, D. (1987). The Consequences of Different Strategies for Measuring Tax Evasion Behavior. Journal of Economic Psychology, 8(3), 311-337.

Emmenegger, P. (2012). How Good Are Your Counterfactuals? Journal of European Social Policy, 21(4), 365-380.

Fiss, P. (2011). Building Better Causal Theories. Academy of Management Journal, 52(2), 393-420.

Fletcher, A., McCulloch, K., Baulk, D., \& Dawson, D. (2005). Countermeasures to driver fatigue. Australian and New Zealand Journal of Public Health, 29(5), 471-479.

Goertz, G., \& Mahony, J. (2012). A Tale of Two Cultures. Princeton: Princeton University Press.

Greer, C. R., \& Downey, H. K. (1981). Industrial compliance with social legislation investigations of decision rationales. Stillwater: Oklahoma State University.

Gunningham, N., Kagan, R. A., \& Thornton, D. (2003). Shades of Green. Stanford: Stanfort University Press.

Hawkins, K. (1984). Environment and enforcement regulation and the social definition of pollution. Oxford: Oxford University Press.

Hug, S. (2013). Qualitative Comparative Analysis. Political Analysis, 21(2), 252-265.

Hutter, B. M. (1997). Compliance regulation and environment. Oxford: Oxford University Press.

Kagan, R. A., \& Scholtz, J. (1984). The 'criminology of the corporation' and regulatory enforcement strategies. In K. Hawkins \& J. M. Thomas (Eds.), Enforcing regulation (pp. 67-97). Boston: Kluwer-Nijhof.

Kahneman, D. (2011). Thinking Fast and Slow. New York: Farrar, Straus and Giroux.

Kirchler, E., Hoelzl, E., \& Wahl, I. (2008). Enforced versus voluntary tax compliance. Journal of Economic Psychology, 29(2), 210-225.

Kirk, W., \& Hawkins, R. (1986). Perceptual Research on General Deterrence. Law \& Society Review, 545-572.

Layder, D. (2006). Understanding Social Theory. London: Sage.

Lee, E. (2008). Socio-Political Contexts, Identity Formation, and Regulatory Compliance. Administration \& Society, 40(7), 741-769.

Lehmann Nielsen, V., \& Parker, C. (2012). Mixed Motives. Law \& Policy, 34(4), 428-462.

Lijphart, A. (1971). Comparative Politics and the Comparative Method. The American Political Science Review, 65(3), 682-693.

Marx, A. and A. Dusa (2011). Crisp-Set Qualitative Comparative Analysis (csQCA), Contradictions and Consistency Benchmarks for Model Specification. Methodological Innovations Online 6(2): 103-148.

May, P. (2004). Compliance Motivations. Law \& Society Review, 38(1), 41-68. 
May, P. (2005). Regulation and Compliance Motications. Public Administration Review, 65(1), 31-44. McGraw, K., \& Scholz, J. T. (1991). Appeals to civic virtue versus attention to self-interest. Law \& Society Review, 25(4), 471-493.

Moses, J., \& Knutsen, T. (2012). Ways of Knowing. New York: Palgrave.

Nagin. (2013). Deterrence in the Twenty-First Century. Crime and Justice, 42(1), 199-263.

Parker, C., \& Nielsen, V. (2009). The Challenge of Empirical Research on Business Compliance in Regulatory Capitalism. Annual Review of Law and Social Science, 5(1), 45-70.

Ragin, C. (2008). Redesigning Social Inquiry. Chicago: Chicago University Press.

Ragin, C., \& Becker, H. S. (1992). What is a Case? Cambridge: Cambridge University Press.

Ragin, C., \& Davey, S. (2014). fs/QCA (Version Version 2.5). Irvine, CA: University of California.

Reiss, A. (1984). Selecting Strategies of Social Control Over Organizational Life. In K. Hawkins \& J. M. Thomas (Eds.), Enforcing regulation (pp. 23-35). Boston: Kluwer-Nijhoff.

Rihoux, B., \& Marx, A. (2013). QCA, 25 Years after 'The Comparative Method'. Political Research Quarterly, 66(1), 167-235.

Rihoux, B., \& Ragin, C. (2009). Configurational Comparative Analysis. London: Sage.

Schneider, C., \& Wagemann, C. (2012). Set-Theoritic Methods for the Social Sciences. Cambridge: Cambridge University Press.

Scholz, J. T., \& Lubell, M. (1999). Trust and taxpaying. American Journal of Political Science, 42(2), 398-417.

Statistical Bureau of Hunan. (2012). Hunan Shucai Canye Fazhan Xianzhung Ji Fazhan Duice Yanjiu ( 湖南蔬菜产业现状及发展对策研究/Study on Vegetable Industry in Hunan Province). Hunan: Hunan Xinxi Wang. Available from: http://www.hntj.gov.cn/fxbg/2012fxbg/2012jczx/201207/t20120718_94402.htm (last accessed 1 June 2015)

Thornton, D., Gunningham, N., \& Kagan, R. (2005). General deterrence and corporate environmental behavior. Law \& Policy, 22(2), 262-288.

Tyler, T. R. (1990). Why people obey the law. New Haven: Yale University Press.

Tyran, J., \& Feld, R. (2002). Why people obey the law. Munich: Centre for Economic Studies.

Van der Berg, M. (2003). Beyond elegance. Stanford Environmental Law Journal, 22(1), 55-144.

Vis, B. (2012). The Comparatve Advantages of fs QCA and Regression Analysis for Moderately Large-N analyses. Sociological Methods and Research, 41(1), 168-198.

Warren, J., Wistow, J., \& Bambra, C. (2013). Applying Qualitative Comparative Analysis (QCA) to evaluate a public health policy initiative in the North East of England. Policy and Society, 32(4), 289-301.

Williams, D. (2005). The relevance of legal awareness in e-commerce security. Journal of Database Marketing, 8(3), 217-223.

Winter, S. C., \& May, P. J. (2001). Motivation for Compliance with Environmental Regulations. Journal of Policy Analysis and Management, 20(4), 675-698.

Yin, R. K. (2003). Case Study Research. Design and Methods (3 ed.). Thousand Oaks: Sage Publications. 